\title{
Fluidized Beds for Concentrated Solar Thermal Technologies-A Review
}

\author{
Claudio Tregambi ${ }^{1,2}$, Maurizio Troiano ${ }^{1}$, Fabio Montagnaro ${ }^{3}$, Roberto Solimene ${ }^{4 *}$ and \\ Piero Salatino $^{1}$ \\ ${ }^{1}$ Dipartimento di Ingegneria Chimica, dei Materiali e della Produzione Industriale, Università degli Studi di Napoli Federico II, Napoli, \\ Italy, ${ }^{2}$ Dipartimento di Ingegneria, Università degli Studi del Sannio, Benevento, Italy, ${ }^{3}$ Dipartimento di Scienze Chimiche, \\ Università degli Studi di Napoli Federico II, Complesso Universitario di Monte Sant'Angelo, Napoli, Italy, ${ }^{4}$ Istituto di Scienze e \\ Tecnologie per l'Energia e la Mobilità Sostenibili, Consiglio Nazionale delle Ricerche, Napoli, Italy
}

OPEN ACCESS

Edited by:

Yulong Ding,

University of Birmingham,

United Kingdom

Reviewed by:

Franz Winter,

Vienna University of Technology,

Austria

Yong Shuai,

Harbin Institute of Technology, China

Qibin Liu,

Institute of Engineering

Thermophysics (CAS), China

${ }^{*}$ Correspondence:

Roberto Solimene

roberto.solimene@cnr.it

Specialty section:

This article was submitted to

Process and Energy Systems

Engineering,

a section of the journal

Frontiers in Energy Research

Received: 16 October 2020

Accepted: 11 January 2021

Published: 08 April 2021

Citation:

Tregambi C, Troiano M, Montagnaro F, Solimene $R$ and Salatino $P$ (2021)

Fluidized Beds for Concentrated Solar

Thermal Technologies - A Review.

Front. Energy Res. 9:618421.

doi: 10.3389/fenrg.2021.618421
Thermal and thermochemical processes can be efficiently developed and carried out in fluidized beds, due to the unique properties of fluidized suspensions of solid particles and to the inherent flexibility of fluidized bed design and operation. Coupling fluidization with concentrated solar power is a stimulating cross-disciplinary field of investigation, with the related issues and opportunities to explore. In this review article the current and perspective applications of fluidized beds to collection, storage and exploitation of solar radiation are surveyed. Novel and "creative" designs of fluidized bed solar receivers/reactors are reported and critically discussed. The vast field of applications of solar-driven fluidized bed processes, from energy conversion with thermal energy storage, to solids looping for thermochemical energy storage, production of fuels, chemicals and materials, is explored with an eye at past and current developments and an outlook of future perspectives.

Keywords: concentrated solar power, solar energy, particle receivers, thermal energy storage, fluidized beds, thermochemical energy storage, solar-driven chemical processes, solar fuels

\section{INTRODUCTION}

Even though cyclic changes in the atmospheric $\mathrm{CO}_{2}$ concentration have characterized the history of our planet, a maximum "physiological" value of about $280 \mathrm{ppm}$ is documented until the beginning of the Industrial Revolution. The much greater values measured nowadays ( $>400 \mathrm{ppm})$ are related to anthropogenic activities, with a dominance of energy conversion processes. The environmental, economic, social, geo-political and ethical consequences of climate change are well established. In 1995 the Intergovernmental Panel on Climate Change (IPCC) published a set of National Greenhouse Gas Inventory guidelines, revised in 2006 and further updated in 2019 (IPCC, 2006; IPCC, 2019). Possible pathways aiming at limited increase of the global average temperature keep greenhouse gaseous emissions to $25-30 \mathrm{GtCO}_{2} \mathrm{e} \mathrm{yr}{ }^{-1}$ in 2030. The decrease in anthropogenic $\mathrm{CO}_{2}$ emissions to the atmosphere and the increase in the use of renewable energies are two pillars which the strategies to face climate change effects are based on.

\footnotetext{
Abbreviations: ASU, air separation unit; CaL, calcium looping; CCSU, carbon capture and sequestration or utilization; CHP, combined heat and power; CSP, concentrated solar power; DIFBAR, directly irradiated fluidized bed autothermal reactor; $\mathrm{d}_{\text {Sauter, }}$ mean Sauter particle size [L]; FB, fluidized bed; HTF, heat transfer fluid; IPCC, intergovernmental panel on climate change; LCA, life cycle assessment; LCOE, levelized cost of electricity; LHV, lower heating value; LT, left tower; PV, photovoltaic; RT, right tower; TCES, thermochemical energy storage; TES, thermal energy storage; TRL, technological readiness level; $\mathrm{X}_{\mathrm{C}}$, carbon conversion [-]
} 
Limiting warming below $1.5^{\circ} \mathrm{C}$ by 2100 relies on large-scale deployment of $\mathrm{CO}_{2}$ emission prevention or remediation. Outlooks based on no or limited overshoot with respect to $1.5^{\circ} \mathrm{C}$ require, by the year 2030, a decline of about $45 \%$ (with respect to 2010 levels) of the global net anthropogenic $\mathrm{CO}_{2}$ emissions, with the aim to reach net zero $\mathrm{CO}_{2}$ emissions around the year 2050 (Rogelj et al., 2018). Carbon Capture and Sequestration or Utilization (CCSU) provides alternative routes to decarbonization (Boot-Handford et al., 2014), either through novel schemes for energy conversion that generate streams of concentrated $\mathrm{CO}_{2}$ (e.g. oxy-fuel or chemical looping combustion), or by removal and concentration of $\mathrm{CO}_{2}$ from $\mathrm{CO}_{2}$-lean effluents (e.g. absorption/desorption with chemical reaction; calcium looping via carbonation/ calcination). Similar technologies may be combined with gasification and/or reforming of fossil fuels (Marra et al., 2017; Troiano et al., 2017b; Troiano et al, 2019; Troiano et al., 2020b). The common goal is to obtain a $\mathrm{CO}_{2}$-rich gaseous stream that can be either geologically stored or reused to obtain products of interest (e.g. methanol, methane, syn-gas, urea). Comprehensive analyses (e.g. by LCA) are required to assess the extent to which these paths are environmentally benign in terms of overall production of $\mathrm{CO}_{2}$. Moreover, the TRLs of the different options may span from 2 to 3 (ocean/mineral storage), to 6-7 (chemical looping combustion/calcium looping and oxy-fuel combustion, respectively) and 9 (absorption/desorption case; $\mathrm{CO}_{2}$ storage in deep saline formations; enhanced oil recovery as a mean for geological storage).

Substitution of fossil fuels with biomass represents another important option toward decarbonization and increased share of renewables. Environmental and socio-ethical issues may arise from extensive exploitation of biomass, especially when possible competition with food and unbalance of carbon in soil are concerned. Exploitation of residual non-food biomass is clearly the path to go, fully consistent with the growing awareness and sensitivity toward circular economy.

For the target of $32 \%$ of renewable energy share by year 2030 (as set by EU directives) to be reached, solar and wind power must extensively come through. PhotoVoltaic (PV) technologies are growing fast, with a current worldwide installed capacity of about $600 \mathrm{GW}_{\mathrm{e}}$ in 2019. Extensive substitution of PV in power generation is currently hampered by low dispatchability of the produced energy, which is stimulating the development of more powerful electrical storage systems (batteries, capacitors) as well as Power-To-X solutions. Concentrated Solar Power (CSP) represents an alternative path to exploit solar energy (REN21, 2020). It is comparatively less deployed mostly due to the higher capital costs, with a current installed capacity of about $6 \mathrm{GW}_{\mathrm{e}}$. Despite being more capital-intensive, CSP is characterized by some attractive features that might justify its use:

- exploitation of the whole solar spectrum, rather than selected spectral ranges only;

- hybridization/integration with other renewable energy sources;

- improved power dispatchability by coupling with energy storage systems. Thermal Energy Storage (TES) and
ThermoChemical Energy Storage (TCES) open the path to uncoupling solar energy collection and final energy uses;

- generation of valuable high-temperature heat, that can be used as process heat or also in hybrid schemes based on the coupling of CSP with energy-intensive physical or chemical processes;

- smaller requirements for critical raw materials if compared to competing technologies (Valero et al., 2018).

CSP has become more geographically diverse in terms of location of commercial plants as well as origin of developers, investors and contractors. The spread of markets around the world, the broadening of supply chains and the accumulated expertise is bringing about a noticeable cost reduction. Figure 1 reports the global Levelized Cost of Electricity (LCOE) and the capacity factor for CSP since 2010 to 2019 (IRENA, 2020). LCOE in 2019 was almost $50 \%$ lower than in 2010 , while the capacity factor increased in the last two years thanks to a higher number of new installations and to the coupling with TES systems.

Energy storage is recognized as a key technology for a decarbonized economy by the European Commission Energy Roadmap 2050. Nearly all the commercial CSP capacity under construction by the end of 2019 will include thermal energy storage. Coupling CSP with TES provides both environmental and economic benefits by reducing the need for burning fuels, improving plant economics and integration of variable renewable electricity in power systems (Zhang et al., 2016a; Alva et al., 2018). Generation capacity is increased as the excess power available during low demand periods can be used to charge a TES system and given back during high-demand periods (Medrano et al., 2010). Figure 2 reports the global TES capacity together with annual additions for the decade 2009-2019 (REN21, 2020). More than $95 \%$ of global TES capacity in operation on CSP plants is based on molten salt technology, the remainder using steambased storage. Figure 2 shows that in the last 2 years a growth of the TES capacity from 12.8 to $21.2 \mathrm{GWh}$ has been registered.

The basic TES is operated by the heating of storage media (by either sensible or phase change latent heat) during a charging period; then, the heat is released when energy is needed (Zhang et al., 2016a), compensating the gap between energy supply and demand. Traditional Heat Transfer Fluids (HTFs) include molten salts, thermal fluids, water/steam and gas, but granular solids are currently gaining consideration as heat transfer/storage media. Currently, the benchmark of CSP/TES technologies is based on the use of molten salts (typically a binary mixture of $\mathrm{NaNO}_{3}$ and $\mathrm{KNO}_{3}$ ) which act as both HTF and heat storage medium in the $290-565^{\circ} \mathrm{C}$ temperature range. Salts solidification/degradation dictate the temperature operability limits. Molten salts show a limiting maximum temperature of $565^{\circ} \mathrm{C}$, that strongly influences the efficiency of the thermodynamic cycle for power generation. Currently, research aims at the study of novel HTFs which would be able to overcome the limits imposed by the use of molten salts, so allowing to increase the efficiency of the solar energy storage systems. Use of granular materials as HTF is a rapidly expanding field: temperatures higher than $1,000^{\circ} \mathrm{C}$ can be tolerated by solid particles of different chemical composition (Ho, 2016). 


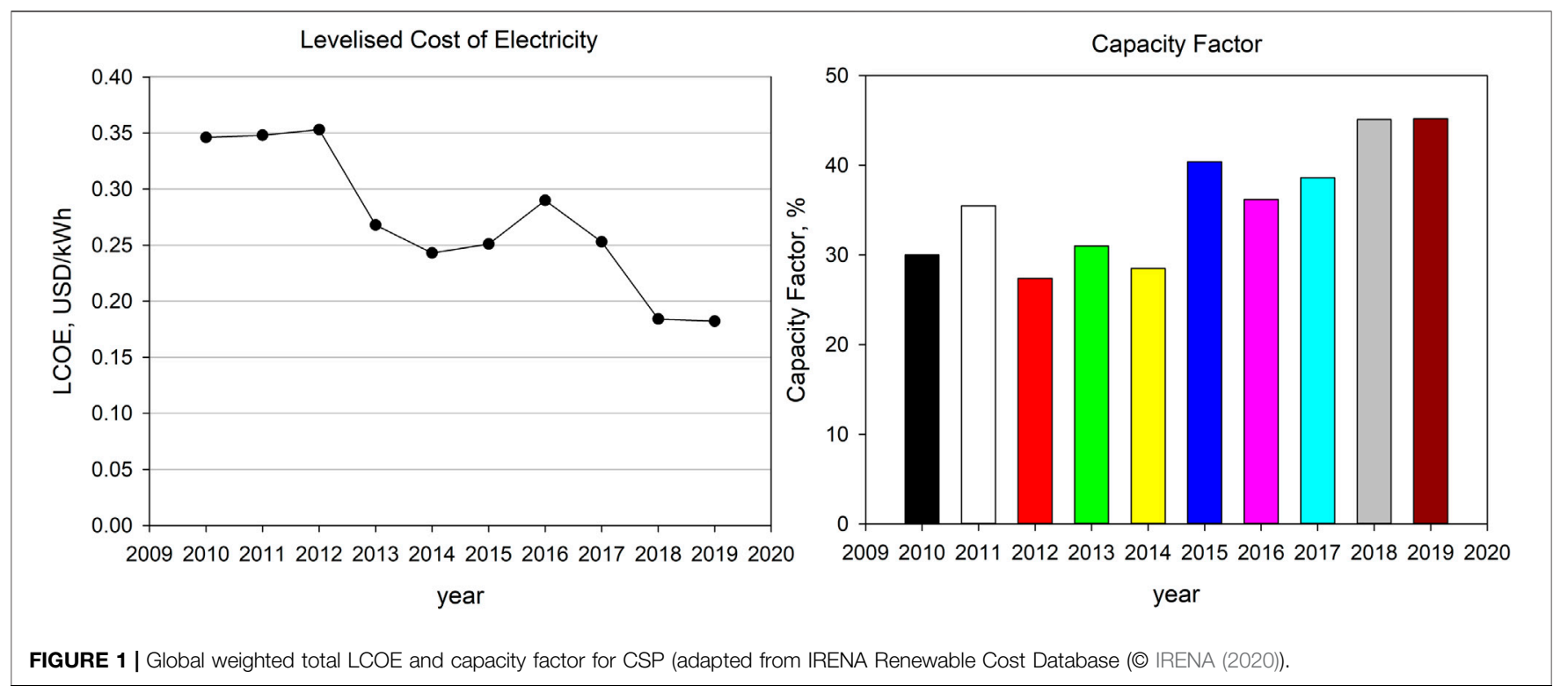

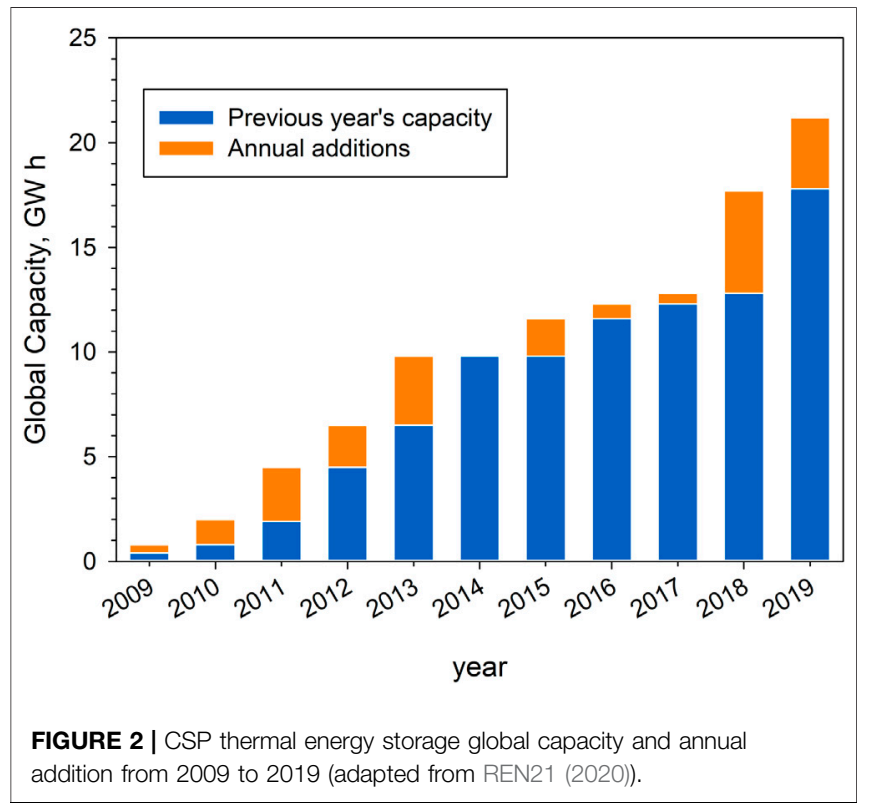

A rapidly expanding subdomain of TES is represented by TCES, which allows to store the concentrated solar energy in the noble and stable form of enduring chemical bonds (André et al., 2016; Bayon et al., 2018; Carrillo et al., 2019). This is done through a reversible chemical reaction having large reaction heat. For TCES systems, the effective recovery of sensible heat through alternated cycles operated at different temperature is pivotal for the improvement of the efficiency of the process (Falter and Pitz-Paal, 2018; Lu et al., 2019). TCES systems are bound to play a major role in the very next future as they enable large energy density and, at least virtually, a time scale of energy storage and dispatchability that can be considered unlimited (Chen et al., 2018; Sunku Prasad et al., 2019). This assures energy programmability also for seasonal changes and favors the solar power dispatchability also through the production of solar-driven energy carriers such as solar fuels/chemicals. The use of solid particles as HTF is very attractive in the context of TCES for the variety of energy-intensive heterogeneous and solid-state reactions on which reversible storage of high-temperature, hence high-quality energy may be based.

Altogether, exploitation of high-temperature solar thermal power from CSP coupled with energy storage is no doubt a "hot" research topic. The development of better and cheaper CSP/ TES systems is a strongly interdisciplinary challenge entailing effective integration of optics, material science, thermodynamics and heat transfer, process hydrodynamics. The expanding domain of CSP/TCES may exploit a broad range of solardriven thermochemical processes. In this lively and expanding field of research and development, fluidization technology has already demonstrated its great potential and role. Fluidization has been successfully applied to several thermal and thermochemical processes (Salatino and Solimene, 2017; Troiano et al., 2020a; Agu et al., 2020), thanks to the unique properties of fluidized suspensions of solid particles and to the inherent flexibility of fluidized bed (FB) design and operation. Application of FBs for solar radiation collection and thermal storage in CSP systems is a challenging field with related issues and opportunities. The past, current and forthcoming applications of FBs in this fertile and cross-disciplinary field are hereby surveyed and discussed.

\section{FLUIDIZED BED SOLAR RECEIVERS AND REACTORS: BASIC DESIGN AND OPERATIONAL FEATURES}

\section{Particle Receivers and Fluidized Beds}

Solar particle receivers/reactors are gaining extensive consideration in CSP applications, as solid particles can work as both HTF in the receiver, heat transfer and storage medium 
TABLE 1 | Outline of fluidized bed technologies for CSP applications.

\begin{tabular}{|c|c|c|c|c|c|c|c|c|c|c|c|}
\hline \multirow[t]{2}{*}{ Type } & & \multirow[t]{2}{*}{ Technology } & \multirow{2}{*}{$\begin{array}{l}\text { Fluidization } \\
\text { regime }^{a}\end{array}$} & \multirow{2}{*}{$\begin{array}{c}\text { Solids } \\
\text { mixing } \\
\text { pattern }^{b}\end{array}$} & \multirow{2}{*}{$\begin{array}{c}\text { Optical } \\
\text { arrangement }^{c}\end{array}$} & \multirow{2}{*}{$\begin{array}{c}\text { Bed } \\
\text { heating }^{d}\end{array}$} & \multirow{2}{*}{$\begin{array}{c}\text { Temperature } \\
\text { range } \\
\text { tested } \\
{\left[^{\circ} \mathrm{C}\right]}\end{array}$} & \multicolumn{2}{|c|}{ Solar input ${ }^{\mathbf{e}}$} & \multicolumn{2}{|c|}{ Application ${ }^{f}$} \\
\hline & & & & & & & & $\begin{array}{c}\text { Average } \\
\text { flux } \\
{\left[\mathrm{kW}_{\mathrm{th}} / \mathrm{m}^{2}\right]}\end{array}$ & $\begin{array}{l}\text { Power } \\
{\left[\mathbf{k W}_{\mathrm{th}}\right]}\end{array}$ & Tested & Projected \\
\hline \multirow[t]{3}{*}{ Ordinary } & A & $\begin{array}{l}\text { Captive/ } \\
\text { Bubbling }\end{array}$ & Bubbling & WS & $\mathrm{BD} / \mathrm{TT} / \mathrm{SF}$ & $\mathrm{DH} / \mathrm{IH}$ & $500-1,500$ & $\begin{array}{c}200-600 \\
\text { (S; OS) }\end{array}$ & $\begin{array}{l}0.5-50 \\
\text { (S; OS) }\end{array}$ & $\begin{array}{l}\text { C; G; PG; } \\
\text { TCES; } \\
\text { TCS; TES }\end{array}$ & - \\
\hline & B & Captive/Spouted & Spouted & WS & $\mathrm{BD} / \mathrm{TT}$ & $\mathrm{DH} / \mathrm{IH}$ & $1,100-1,400$ & $\begin{array}{c}10,000^{P} \\
(\mathrm{OS})\end{array}$ & $1.5(\mathrm{OS})$ & $\mathrm{G}$ & \\
\hline & C & Circulating & Fast & $\mathrm{RR}$ & Lateral & $\mathrm{DH}$ & $125-200$ & - & 4-10 (OS) & PG & - \\
\hline \multirow[t]{7}{*}{$\begin{array}{l}\text { Special } \\
\text { design }\end{array}$} & D & Compartmented & Bubbling & WS & $\mathrm{BD}$ & $\mathrm{DH} / \mathrm{IH}$ & $400-620$ & $350(\mathrm{OS})$ & $\begin{array}{c}100-2,000 \\
(\mathrm{OS})\end{array}$ & PG; TES & $\mathrm{HC}$ \\
\hline & $E$ & Particle-in-tube & Bubbling & $\mathrm{DF}$ & $\pi$ & $\Vdash H$ & $500-750$ & $\begin{array}{l}200-500 \\
\text { (OS) }\end{array}$ & $\begin{array}{c}10-150 \\
\text { (OS) }\end{array}$ & PG; TES & - \\
\hline & $\mathrm{F}$ & $\begin{array}{l}\text { Internal } \\
\text { circulation }\end{array}$ & Bubbling & $\mathrm{RR}$ & $\mathrm{BD}$ & $\mathrm{DH}$ & $900-1,400$ & $\begin{array}{c}700-1,600 \\
(\mathrm{~S}) \\
500^{\mathrm{g}}(\mathrm{OS})\end{array}$ & $\begin{array}{l}1-30(\mathrm{~S}) \\
100(\mathrm{OS})\end{array}$ & TCS; G & - \\
\hline & $G$ & Two-tower & Bubbling & WS & $\mathrm{BD}$ & $\mathrm{DH}$ & $900-1,400$ & - & - & - & PG; TES \\
\hline & $\mathrm{H}$ & $\begin{array}{l}\text { Multistage } \\
\text { horizontal }\end{array}$ & Bubbling & $\begin{array}{l}\mathrm{PF} / \\
\mathrm{DF} / \mathrm{CF}\end{array}$ & $B D+L F R$ & $\mathrm{DH}$ & 200-800 & - & - & - & PG/TES \\
\hline & I & $\begin{array}{l}\text { Multistage } \\
\text { horizontal }\end{array}$ & Bubbling & $\begin{array}{l}\mathrm{PF} / \\
\mathrm{DF} / \mathrm{CF}\end{array}$ & $\mathrm{SF}(T T)$ & $\mathrm{H}$ & 815 & $220(\mathrm{OS})$ & 45-65 (OS) & C & - \\
\hline & J & Autothermal & $\begin{array}{l}\text { Bubbling/ } \\
\text { Spouted }\end{array}$ & $\begin{array}{l}\text { WS/ } \\
\text { DF/PF }\end{array}$ & BD/PD & $\mathrm{DH}$ & $500-1,200$ & $250(\mathrm{~S})$ & $2(\mathrm{~S})$ & TCES & G; P; TCS \\
\hline
\end{tabular}

"The fluidization regime refers to the "active" part of the bed.

${ }^{b} \mathrm{CF}$, compartmented flow; $D F$, dispersed flow; PF, plug flow; RR, recycle reactor; WS, well stirred.

${ }^{c} B D$, beam down; $L F R$, linear fresnel reflector; $P D$, parabolic dish; SF, solar furnace; $\Pi$, tower top.

${ }^{d} \mathrm{DH}$, direct irradiation of the bed; $I H$, indirect heating of the bed.

${ }^{e} \mathrm{OS}$, on sun; S, simulated.

${ }^{f} \mathrm{C}$, calcination; HC, hybridization with biogas combustion; G, gasification; P, pyrolysis; PG, power generation; TCS, thermo-chemical splitting; TES, thermal energy storage; TCES, thermochemical energy storage.

${ }^{g}$ Peak value.

(Alonso and Romero, 2015; Ho, 2016; Zhang et al., 2017; Kang et al., 2018; Reed et al., 2018; Kang et al., 2019), absorbing and withstanding radiative fluxes of several $\mathrm{MW} \mathrm{m}^{-2}$ and, finally, as reactant in many TCES processes involving gas-solid chemical reactions. This last aspect is calling for further efforts in a proper design of multiphase chemical reactors. As matter of fact, the development of novel reactor concepts (Alonso and Romero, 2015; Kodama et al., 2017a; Zsembinszki et al., 2018; Arastoopour, 2019) that can be effectively coupled with CSP systems has been reported in the recent literature. Cyclonic, free-falling particles, fixed, fluidized and mobile beds, and rotary receivers/reactors in directly and indirectly irradiated configurations have been extensively taken into account for heating of particles and for chemical reactions appropriate to TCES and production of solar fuels (Marxer et al., 2015; Ho, 2016; Koepf et al., 2016; Davis et al., 2019a; Davis et al., 2019b; Davis et al., 2020). Falling particle receivers/reactors can be attractive as it does not entail a gas stream for particle motion, with related advantages in terms of operation expenses. Research aims at increasing the residence time of particles, as this would allow higher falling particles temperatures. The determination of the most appropriate properties for the particle curtain is crucial to achieve an increase in solar absorption with the reduction of the heat losses related to scattering and reflection phenomena. The wind effect on the flow of particles is also under investigation. Packed bed or porous solid structured reactors benefit of low cost and offer reduced problems of solids attrition and erosion, but the drawbacks related to inefficient heat and mass transfer, nonuniform irradiance distribution on the particle volume, and more complex scale-up criteria must be underlined (Cho et al., 2015; Marxer et al., 2015; Deutsch et al., 2017; Tescari et al., 2017; Arribas et al., 2018; Guene Lougou et al., 2018; Zsembinszki et al., 2018; Almendros-Ibáñez et al., 2019; Guene Lougou et al., 2020; Peng et al., 2020; Shuai et al., 2020). As far as rotary kilns are concerned, they are characterized by long life of the main components, with not high maintenance costs and high versatility when particle shape, size and composition are taken into account (Alonso et al., 2017; Montagnaro et al., 2018).

Fluidization technology can prove a long story of successful thermal and thermochemical applications. This has favored the expansion of FB systems also to novel fields. FBs have been employed for solar energy applications, considering configurations operating in bubbling, spouted, circulating regimes (see Table 1, Types A-C “ordinary” configurations), and special and novel designs (Types D-J). Early studies successfully pioneered the application of ordinary FBs operated in the bubbling (Flamant, 1982; Bachovchin et al., 1983) and circulating (Koenigsdorff and Kienzle, 1991; Werther et al., 1994) regimes (Table 1, Types A and C). The remarkable thermal properties of FBs associated with the 
inherent mobility of fluidized particles received further confirmation in subsequent studies (Flamant et al., 1988; Glicksman et al., 1988; Chirone et al., 2013; Pardo et al., 2014; Schwaiger et al., 2014; Salatino et al., 2016; Tregambi et al., 2016; Milanese et al., 2017a; Tregambi et al., 2018a; Briongos et al., 2018; Miller et al., 2018; Bellan et al., 2019a; Tregambi et al., 2019a; Almendros-Ibáñez et al., 2019; Zhang and Wang, 2019; Sulzgruber et al., 2020a; Díaz-Heras et al., 2020b; Sulzgruber et al., 2020b; Park et al., 2020; Wünsch et al., 2020). Moreover, FBs, if properly designed and operated, may provide an appropriate environment for solar-driven heterogeneous chemical processes. The FBs potential was recognized and reported as early as in ' 80 s (Flamant et al., 1980; Flamant, 1982; Flamant and Olalde, 1983; von Zedtwitz and Steinfeld, 2005; Gomez-Garcia et al., 2017) and FB reactors were operated with success at lab-scale for the production of solar fuels/ chemicals (von Zedtwitz et al., 2007; Gokon et al., 2015; Guo et al., 2015; Chuayboon et al., 2018a).

The incident radiative flux interaction with the FB may be either indirect, as solar radiation is concentrated onto a cavity or an exposed surface whence, by convection/conduction, heat is transferred to the suspension of solid particles (Chirone et al., 2013; Benoit et al., 2015), or direct, when solar radiation is directly concentrated onto the fluidized suspension of solid particles through openings or windows and transparent walls, optically accessible (Tregambi et al., 2017; Bellan et al., 2018c). Higher process temperatures are achievable by direct heating (Alonso and Romero, 2015; André et al., 2016; Prieto et al., 2016; Yadav and Banerjee, 2016), but axial/radial temperature gradients inside the bed may occur under operating conditions where the solar radiation is unevenly incident and highly concentrated. This has a potentially negative effect on the performance of reactive materials (Tregambi et al., 2017; Tregambi et al., 2018a; Tregambi et al., 2019d), as overheating of the bed surface brings about sintering, degradation or even ablation of the fluidized particles (Díaz-Heras et al., 2021b).

\section{Special Designs of Fluidized Bed Solar Receivers and Reactors}

Application of FBs to collection and exploitation of concentrated solar radiation poses, at the same time, issues and opportunities to the fluidization community. The potential of this field stimulates re-thinking of some of the typical criteria for design and operation, with the twofold goal of better exploiting the inherently good thermal performances of gas-solid FBs and tailoring fluidization to the specific needs and constraints posed by an expanding and diversified range of applications. Starting from the basic bubbling, spouted and circulating FB technologies (Types A-C in Table 1), "creative" and non-conventional designs and operation of FBs have been explored with the aim of enhancing thermal properties and/or contacting patterns designed around the very demanding context of CSP coupled with thermal and thermochemical processing. Some of the proposed novel solutions represent tailored variants of the dual interconnected FB reactor concept borrowed from "solids looping" processes (e.g. chemical looping combustion/reforming, calcium looping, etc.). A selection of the most successful and best documented solutions is hereby surveyed. Recurrent ordinary and special designs of FBs employed in CSP and solar chemistry applications are outlined in Table 1.

\section{The Compartmented Fluidized Bed Solar Receiver}

Uneven and unsteady fluidization are the keys for enhancing bed thermal diffusivity and bed-to-surface heat transfer (Salatino et al., 2016; Tregambi et al., 2016; Migliozzi et al., 2017) underlying the use of compartmented FB solar receiver with inherent TES. The concept outlined in Figure 3 (Solimene et al., 2017) and Table 1 (Type D) is implemented in a beam-down solar collection/reflection scheme. A bubbling FB is divided in different compartments, each optimized so as to accomplish one of the three complementary tasks of a solar receiver: 1$)$ collection of highly concentrated (100-1,000 suns, where 1 sun $=1 \mathrm{~kW} \mathrm{~m}^{-2}$ ) incident solar radiation; 2) heat transfer to the thermodynamic cycle working fluid for thermo-electrical conversion; 3) TES for leveling off the inherent time-variability of the incident solar radiation. Fluidization conditions in each compartment are optimized so as to enhance thermal diffusivity and bed-tosurface heat transfer around internals (tube bundles, radiation cavities), while minimizing parasitic energy losses (compression work, sensible heat of the fluidizing gas).

One of the challenging tasks of the proposed design is achieving bed compartmentation without having a physical bed confinement and with minimal use of internals. This goal has been pursued proposing a compartmented windbox with independent feeding of the fluidizing gas. In a dedicated experimental campaign (Migliozzi et al., 2017) the effectiveness of uneven bed fluidization by a compartmented gas distributor was tested. Further experiments (Tregambi et al., 2016) were directed to assess the potential of uneven fluidization to improve heat transfer from the highly irradiated beam footprint on the bed, e.g. by fluidizing gas additional feeding and bubbles generation. Díaz-Heras et al. (2021a) confirmed that, in directly irradiated FB, the use of an uneven fluidization strategy can help in reducing the maximum temperature of the fluidized particles, in particular for shallow beds. Fluidization may be optimized so as to keep the very favourable thermal properties of FBs while reducing parasitic energy losses related to the fluidized state (Chirone et al., 2013; Solimene et al., 2017).

The design of the compartmented FB receiver has been complemented by the development of a tailored control strategy to regulate the fluidization state of each compartment so as to accomplish all the basic features of the bed: 1) collection of the incident radiative solar power; 2) TES in a dedicated bed compartment; 3) heat transfer to the working fluid via an internal heat exchanger immersed in the bed; 4) retrieval of the stored thermal energy under no or insufficient solar irradiation (Chirone et al., 2013; Solimene et al., 2017).

The compartmented FB receiver developed at Naples provided the background of the Magaldi beam-down STEM ${ }^{\circledR}$ concept. Two STEM $^{\circledR}$ demonstration plants have been built and successfully operated, one rated at about $100 \mathrm{~kW}_{\text {th }}$, the other at about $2 \mathrm{MW}_{\text {th }}$ peak radiative power. 


\section{Concentrated solar radiation \\ IIIII}

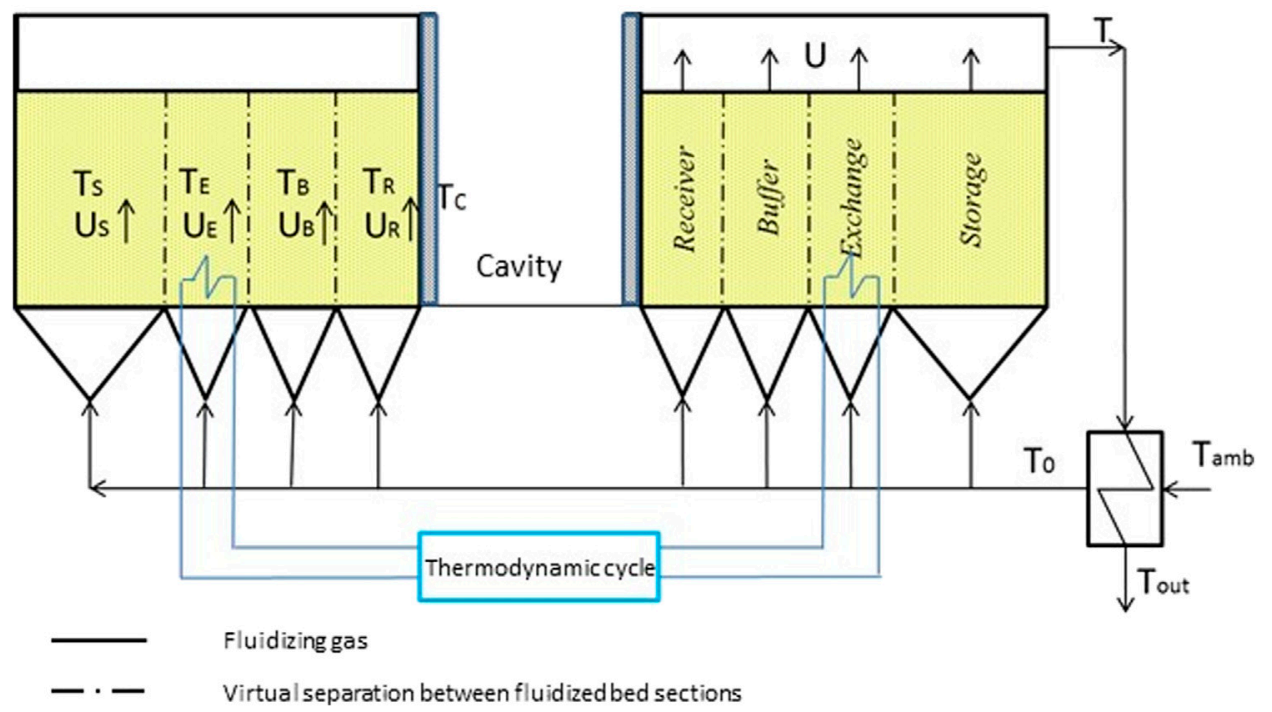

FIGURE 3 | Conceptual representation of the solar receiver/thermal energy storage system based on compartmented dense gas fluidized beds (adapted from Solimene et al. (2017), with the permission of AlP Publishing).

\section{The Fluidized Particle-In-Tube Concept}

Flamant and Hemati (2010) deposited a patent based on a novel concept of CSP with daily TES, reported as Type E in Table 1. Figure 4 shows a schematic of the plant under on-sun and offsun operation. The three complementary tasks (collection, transfer and storage) of a solar receiver are accomplished by a dense gas-solid suspension in three different and complementary units, resembling a typical tower-top solar plant configuration designed for molten salts as HTF with cold/hot tanks for TES. Fluidized particles, rather than molten salts, are used as HTF in the solar receiver to collect thermal energy from the highly concentrated solar beams. The fluidized particles are transported upwards from a pressurized FB dispenser along a series of multiple risers, arranged in parallel, toward a FB collector at the top of a solar tower. Solar beams are concentrated on the external surface of opaque riser tubes, fluidized in bubbling regime. The pressure difference between the freeboard of the FB dispenser and the freeboard of the FB collector drives the motion of the fluidized particles. Accordingly, the dense gas-solid suspension travels along the tubes at fairly large mass flux, $18-200 \mathrm{~kg} \mathrm{~m}^{-2} \mathrm{~s}^{-1}$, yielding good bed-to-wall heat transfer coefficients while keeping low the parasitic heat losses. The base of the riser is aerated to stabilize the flow of the fluidized particles. TES is accomplished by collecting hot particles in an aerated vessel. Heat is transferred to the working fluid by a multistage counter flow FB heat exchanger, where the heat exchanger performance is maximized by approaching counter current plug flow. The key advantage of the fluidized particle-intube concept is the tower-top arrangement which features better optical performance as the secondary reflection of the beamdown configuration is avoided.

The fluidized particle-in-tube concept has been extensively proven, both by on-sun heating of the fluidized particles (Flamant et al., 2013; Benoit et al., 2015; Perez Lopez et al., 2016; Le Gal et al., 2019) and by characterization of the heat transfer mechanisms and hydrodynamics in the riser (Boissiere et al., 2015; Reyes Urrutia et al., 2016; Ansart et al., 2017; GarcíaTriñanes et al., 2018). Operation up to $750^{\circ} \mathrm{C}$, a temperature level much higher than that used in the molten salts solar plant, has been demonstrated. Bed-to-wall heat transfer coefficient in the order of $500-700 \mathrm{~W} \mathrm{~m}^{-2} \mathrm{~K}^{-1}$ with ordinary tubes (Zhang et al., $2016 \mathrm{~b}$ ) and $1,200 \mathrm{~W} \mathrm{~m}^{-2} \mathrm{~K}^{-1}$ with finned tubes (Le Gal et al., 2019) have been reported. The role played by the multistage FB heat exchanger has also been highlighted (Gomez-Garcia et al., 2017). Forthcoming developments are the realization of a $4 \mathrm{MW}_{\text {th }}$ tubular solar receiver to heat particles up to $800^{\circ} \mathrm{C}$, connected to a two-tank particle heat storage and a particle-to-pressurized air heat exchanger coupled with a 1.2 $\mathrm{MW}_{\mathrm{e}}$ gas turbine. Operation of a medium-scale modular solar power plant $(\sim 20 \mathrm{MW})$, that integrates a gas turbine combined cycle with a fluidized particle-in-tube receiver and direct thermal storage has been recently simulated (Behar et al., 2020).

\section{The Internal-Circulation Fluidized Bed Solar Reactor}

Kodama et al. have developed a windowed FB reactor with an internal circulation zone coupled with a beam-down solar optical configuration for thermochemical processes requiring temperatures of $1,000-1,500^{\circ} \mathrm{C}$ (Gokon et al., 2006; Kodama et al., 2008). The schematic of the internally circulating FB 


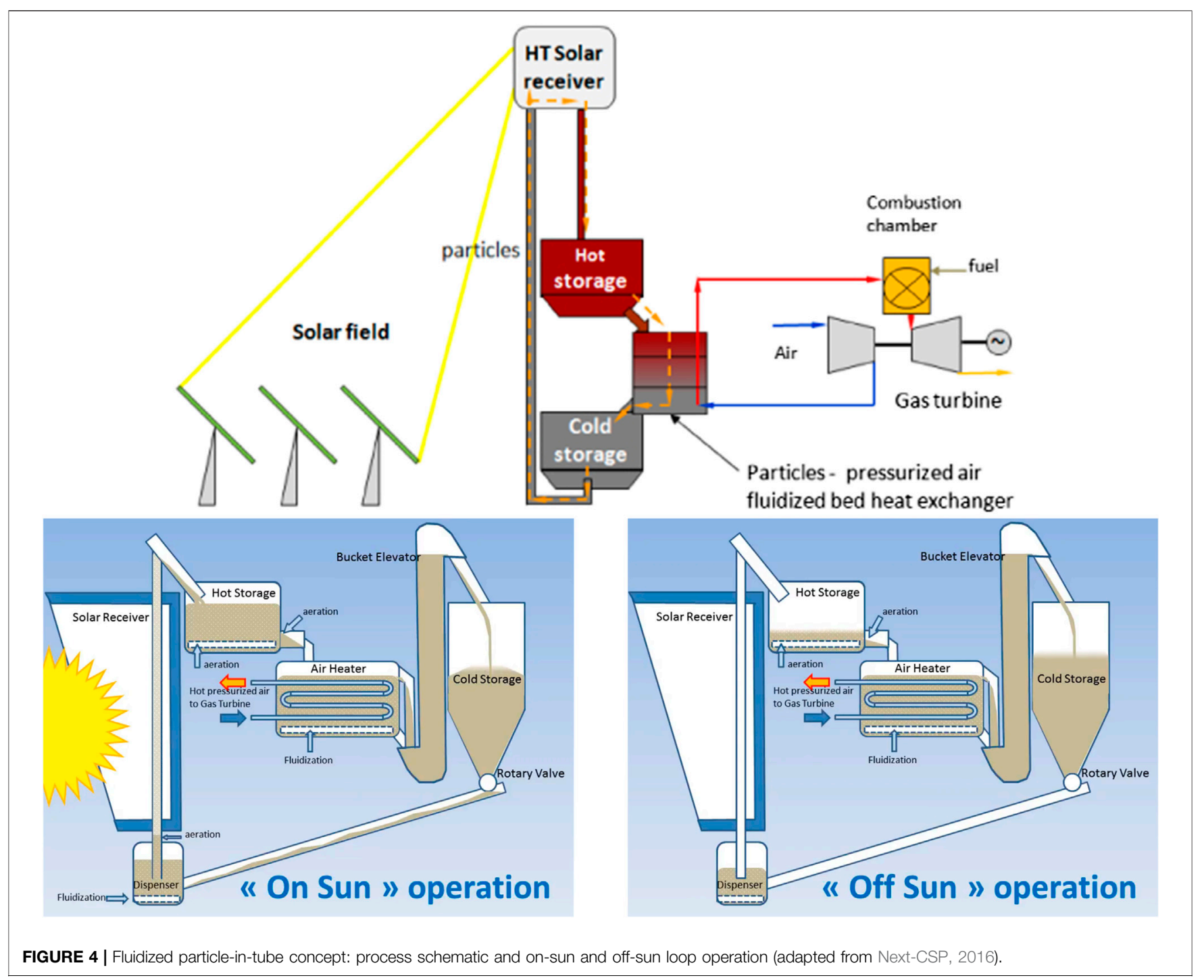

reactor is reported in Figure $\mathbf{5}$ and its main features in Table $\mathbf{1}$ (Type F). The cylindrical body of the prototype reactor is made of stainless steel, with a transparent quartz window installed in the ceiling. In the FB region, a draft tube is centrally inserted. Particles are transported upward in the draft tube and move downward in the annulus region. The draft tube and the annulus are fluidized independently of each other. Solar radiation is concentrated in a beam-down optical arrangement directly on the bed surface, after crossing the enclosing window. Solids circulation promotes effective axial transport of the irradiated power, so that a fairly uniform axial temperature profile is established as compared with a reactor without internal circulation. An additional advantage of this configuration is that only the draft tube requires vigorous fluidization, with positive impact on the parasitic energy losses for the establishment of fluidization. The internal-circulation FB reactor was initially tested at bench-scale using a $1 \mathrm{~kW}_{\text {th }}$ sun simulator for coal coke gasification and water splitting.
Eventually it was scaled up for coupling with a $30 \mathrm{~kW}_{\text {th }}$ solar simulator (Kodama et al., 2016) by replacing the draft tube with a perforated plate distributor and uneven gas distribution. The design of the $100 \mathrm{~kW}_{\text {th }}$ beam-down demonstration solar plant at Miyazaki, Japan, was based on similar design criteria (Kodama et al., 2017b).

\section{The Two-Tower Fluidized Bed Concept}

A novel concept of a two-tower solar FB system has been proposed to be implemented in the $100 \mathrm{~kW}_{\text {th }}$ beam-down demonstration solar plant at Miyazaki (Figure 6 and Table 1, Type G). The system, acting as solar receiver and thermal energy storage (Bellan et al., 2017), consists of a Left fluidized bed Tower (LT) exposed to the solar radiation, interconnected by two slits at the top and the bottom with a Right fluidized bed Tower (RT) mainly devoted to the transport of the heated particles toward the TES stage. The particles of the LT fluidized bed receive radiation through the 


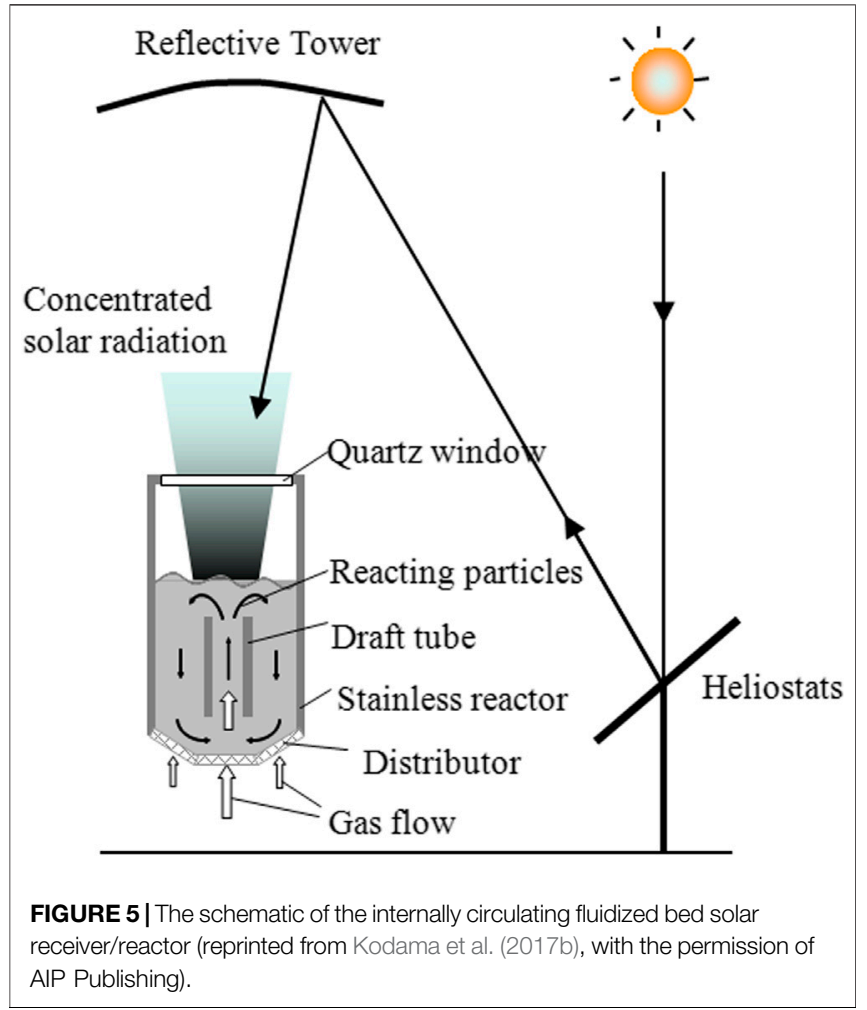

top window and exchange thermal energy with other particles and the heat transfer fluid. The fluidized particles heated in LT gradually move to the RT fluidized bed. Fluidization of the towers is regulated so as to establish solids circulation between the towers. The radiative power drives the performance of the system, and flow pattern and circulation velocity of the fluidized particles between the towers are regulated accordingly. Bellan et al. (2018c) reported a comprehensive hydrodynamic and heat transfer characterization of the twotower FB system.

\section{Multistage Horizontal Fluidized Beds}

The residence time distribution in conventional FB converters is most typically that of a well stirred reactor. In many solardriven physical or chemical processing of granular materials, a narrow residence time distribution of the reacting particles would be desirable to obtain a more standard output product. The linear solar particle receiver and the shallow cross-flow FB reactor are directed to achieve this result (Figure 7; Table 1, Types $\mathrm{H}$ and I).

The linear solar particle receiver consists in a multistage FB system placed at ground level in which the gas flows consecutively through multiple horizontally connected FBs (GómezHernández et al., 2018). The windowed FBs are directly irradiated by a beam-down linear Fresnel optical arrangement (Gómez-Hernández et al., 2018). The stepwise co-current horizontal movement of gas and solids enables the absorption of the solar radiation along the linear receiver. The receiver thermal performance coupled with the beam-down linear
Fresnel reflector has been characterized by Gómez-Hernández et al. (2020).

The shallow cross-flow FB reactor has been proposed for solar calcination processes by Esence et al. (Esence et al., 2020a; Esence et al., 2020b) in a tower-top solar arrangement. The reactor consists of a shallow cross-flow FB, $1 \mathrm{~m}$ long, $80 \mathrm{~mm}$ wide and $165 \mathrm{~mm}$ high, physically split by baffles into 4 in-series equisized compartments (Figure 7). The concentrated solar radiation is focused on the front wall and heat is transferred to the fluidized particles by a combination of heat transfer mechanisms.

\section{The Autothermal Fluidized Bed Reactor}

A novel Directly Irradiated Fluidized Bed Autothermal Reactor (DIFBAR) has been developed at Naples for application to solar chemistry (Table 1, Type J). The concept of the reactor is a FB solar receiver/reactor coupled with a double pipe heat exchanger. The reactor is autothermally operated, to achieve the reaction temperature by reactants preheating at the expense of the products sensible heat via a countercurrent solid-solid heat exchanger, Figure 8. Fluidization allows the recirculation of solids and the efficient recovery of heat. Detailed features of the reactor are: 1) the solids recirculation between two distinct reaction zones is controlled and continuous; the two zones are the solar receiver (here the solid particles are directly irradiated by solar radiative flux), and either one or two bulk FB; 2) two kinds of solid flow pattern can be established in the solar receiver, i.e. "fountain" flow (this allows "volumetric" interaction between the particle-laden flow and the radiative flux), or dense-phase solids overflow from the riser to the dipleg; 3) the reactor is equipped with an internal solid-solid countercurrent heat exchanger with high performance, where the uprising particles are heated up at the expense of the sensible heat of the recirculated particles; 4 ) the solar receiver is gas leaktight with respect to the rest of the reactor, so that different sections of the reactor can be operated with different reaction atmospheres.

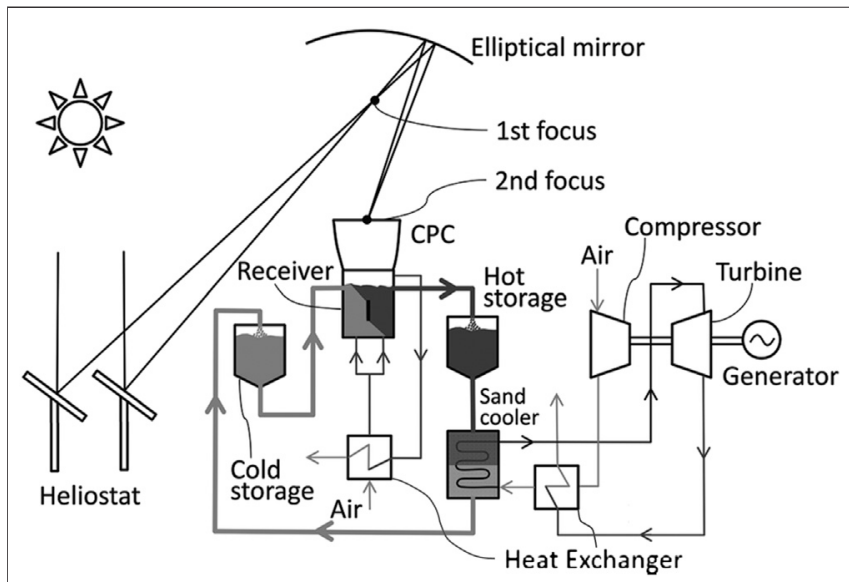

FIGURE 6 | The schematic of the solar generation unit based on the twotower type solar receiver for thermal energy storage (reprinted from Matsubara et al. (2015), with the permission of Elsevier LTD.). 

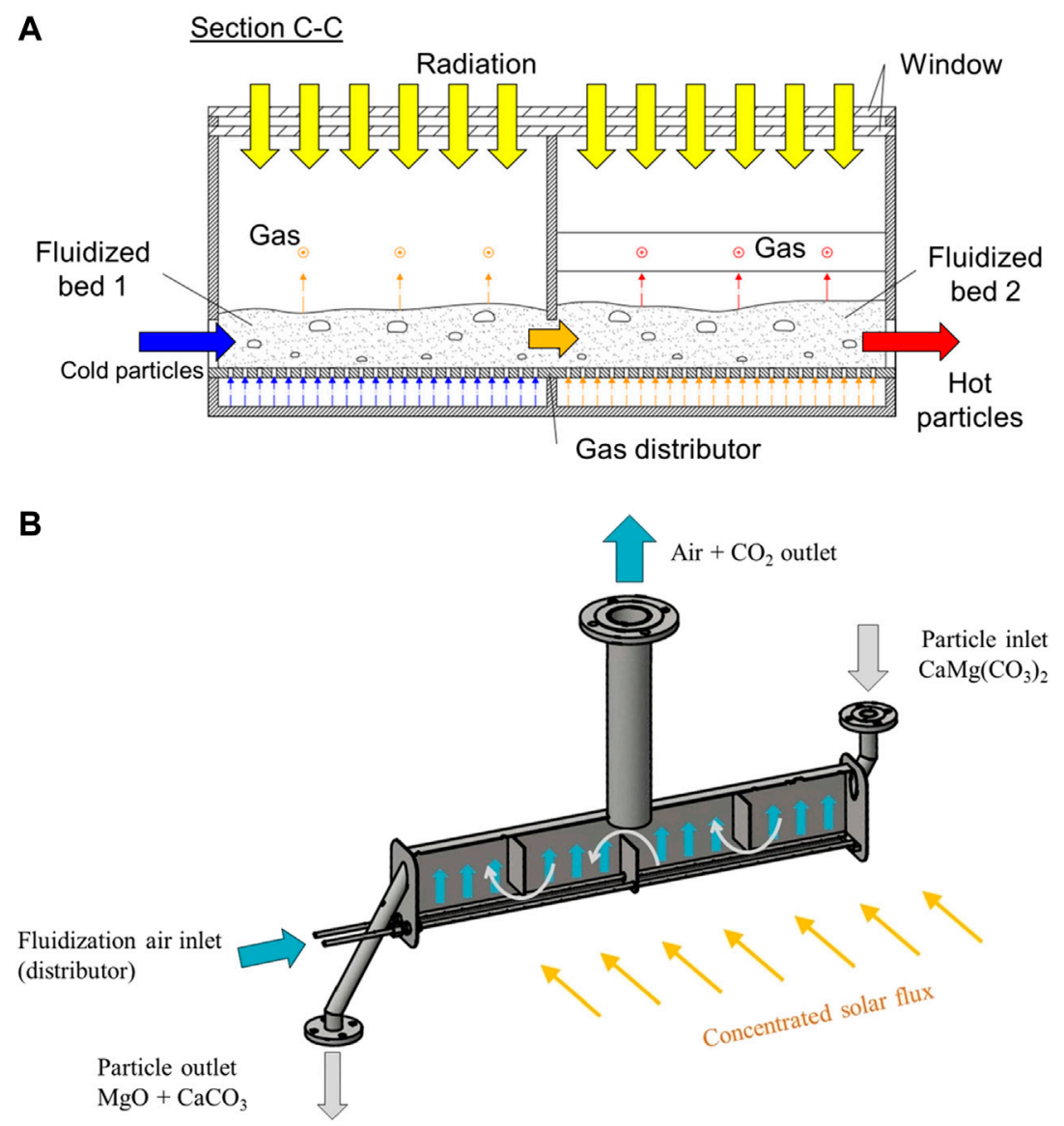

FIGURE 7 | Multistage horizontal fluidized beds: (A) Schematic of the linear solar particle receiver (reprinted from Gómez-Hernández et al. (2018) with the permission of AIP Publishing); (B) The shallow cross-flow fluidized bed reactor (reprinted from Esence et al. (2020a), distributed under a Creative Commons Attribution (CC BY) license).

A proof-of-concept of the reactor has been given operating a lab-scale reactor under reactive and non-reactive conditions (Tregambi et al., 2020a; Tregambi et al., 2020b) and simulated solar radiation. The recirculation of particles between the main FB and the solar receiver has been characterized and related to the carrier gas riser flow rate. An assessment, yet qualitative, of the hydrodynamical patterns of particles ejection-fall back in the receiver section, spanning from fountain flow to dense bed overflow, has been accomplished by infrared thermographic mapping. The overall heat transfer coefficient in the double pipe countercurrent heat exchanger resulted quite large, in the $400-700 \mathrm{~W} \mathrm{~m}^{-2} \mathrm{~K}^{-1}$ range. The effectiveness of heat recovery and of the autothermal operation was successfully demonstrated, providing the basis for further implementation of the concept to industrially relevant processes.

\section{Pulsed and Sound-Assisted Fluidization}

Non-conventional operational modes have been also considered to improve the performance of FB receivers. The potential of uneven fluidization has already been addressed in previous sections. Salatino et al. (2016) discuss the potential of pulsed fluidization, whose remarkable features are: 1) thermal properties can be finely tuned even under operating conditions close to incipient fluidization, varying the time modulation of intermittent fluidization; 2) pulsed beds can have satisfactory thermal properties, similar to those of steadily FBs, even at gas superficial velocities smaller than the incipient value, on a time-average basis. These favourable features have received only limited attention so far in the development of $\mathrm{FB}$ receivers.

Sound-assisted FB in solar-driven chemical processing have been first proposed by De Maria et al. (2001) and further explored by Raganati et al. (2020). Stimulated by the findings of BenitezGuerrero et al. (2017) and Durán-Martín et al. (2020), Raganati et al. (2020) performed Calcium Looping (CaL) experiments in a FB of very fine particles $\left(d_{\text {Sauter }}=4 \mu \mathrm{m}\right)$ to improve material reactivity, hence energy storage density. Acoustic perturbation was effectively applied to break up particle clusters/agglomerates and enable fluidization of the otherwise cohesive powder. Although very favourable, results obtained at the bench scale need careful consideration in view of the scale-up issues of soundassisted FB reactors. 
Single tank

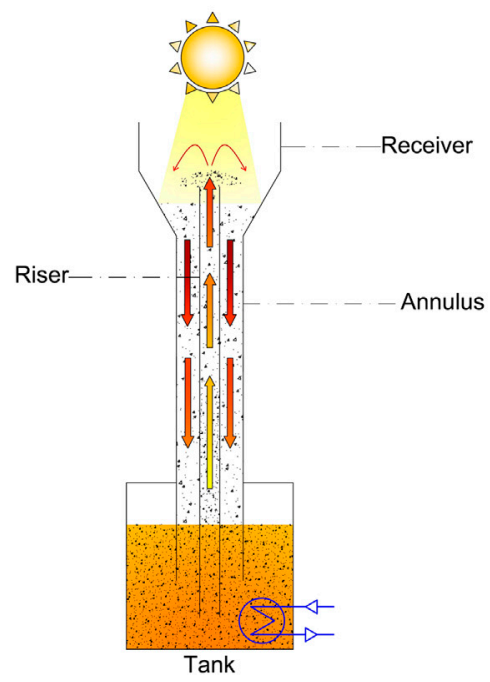

Dual tank

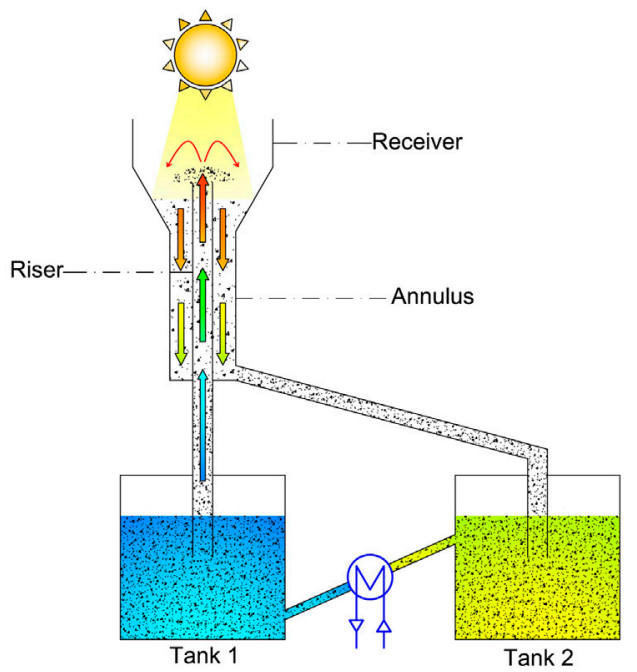

FIGURE 8| The schematic of the directly irradiated fluidized bed autothermal reactor (reprinted from Tregambi et al. (2020a), Copyright (2020) with permission from Elsevier).

TABLE 2 | Comparison of selected properties of fluidized beds with other media.

\begin{tabular}{|c|c|c|c|c|c|c|c|}
\hline & & & Steel & Concrete & Molten salts & Graphite & Fluidized beds \\
\hline$\rho$ & Density & $\mathrm{kg} \mathrm{m}^{-3}$ & 7,800 & 2,200 & 2,000 & 1,600 & $\sim 1,000$ \\
\hline k & Thermal conductivity & 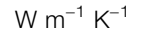 & 40 & 1.5 & 1 & 50 & $\sim 2,000^{\mathrm{a}}$ \\
\hline$c_{p}$ & Specific heat & $\mathrm{kJ} \mathrm{kg}^{-1} \mathrm{~K}^{-1}$ & 0.6 & 0.85 & 1.5 & 1.5 & $\sim 1$ \\
\hline$\alpha$ & Thermal diffusivity & $\mathrm{m}^{2} \mathrm{~s}^{-1}$ & $8.5 \times 10^{-6}$ & $8.0 \times 10^{-7}$ & $3.3 \times 10^{-7}$ & $2.1 \times 10^{-5}$ & $\sim 2 \times 10^{-3 b}$ \\
\hline$h$ & Heat transfer coefficient & $\mathrm{kW} \mathrm{m} \mathrm{m}^{-2} \mathrm{~K}^{-1}$ & n.a. & n.a. & $3-6$ & n.a. & $0.2-1.2^{c}$ \\
\hline
\end{tabular}

\section{PRESENT AND PERSPECTIVE APPLICATIONS OF FLUIDIZED BED SOLAR RECEIVERS AND REACTORS}

\section{Solar Energy Collection With Thermal Energy Storage}

The potential of FBs to act as solar receivers coupled with TES has been widely recognized and reviewed in the recent literature (Zhang et al., 2016a; Alva et al., 2018; Almendros-Ibáñez et al., 2019). Fluidized solids can be exploited as alternative to other HTFs and storage/exchange media, like molten salts or diathermic oils, as they can help in overcoming concerns related to the use of environmentally unfriendly or corrosive fluids, and enable operation at high and very high temperatures. Table 2 compares selected properties of different HTFs, showing the extremely favourable thermal properties of fluidized solids:

(1) the thermal capacity is similar to other TES media;

(2) the bed-to-surface heat transfer coefficient is in the order of hundreds of $\mathrm{W} \mathrm{m}^{-2} \mathrm{~K}^{-1}$ and can be tailored through the proper use of the parameters of fluidization;
(3) effective thermal diffusivities of fluidized solids associated with particle convective phenomena are fairly large, ranging from 0.001 to $0.1 \mathrm{~m}^{2} \mathrm{~s}^{-1}$ (Berruti et al., 1986; Niklasson et al., 2002; Sette et al., 2014).

The thermal diffusivity values are far larger than those typical of most monolithic, granular or fluid media proposed for the collection of solar radiation with TES. This feature may be optimized by the proper choice of particles type and size, and regime of fluidization. Thanks to these favourable thermal properties, FBs may accomplish the three basic tasks of: 1) collection of incident solar radiation with limited re-emission of the incident radiation and local overheating at the radiative beam footprint of the receiver; 2) transfer of the incident power to immersed tube bundles or other internals, for optimal integration in energy conversion cycles; 3) TES, to compensate the inherent time variability of the incident radiation for stationary $\mathrm{CHP}$ generation.

FB solar receivers have been investigated as early as in the ' 80 s, with layouts spanning from the proof-of-concept to the lab-scale levels: dense stationary gas FB, dilute- or dense-phase circulating 

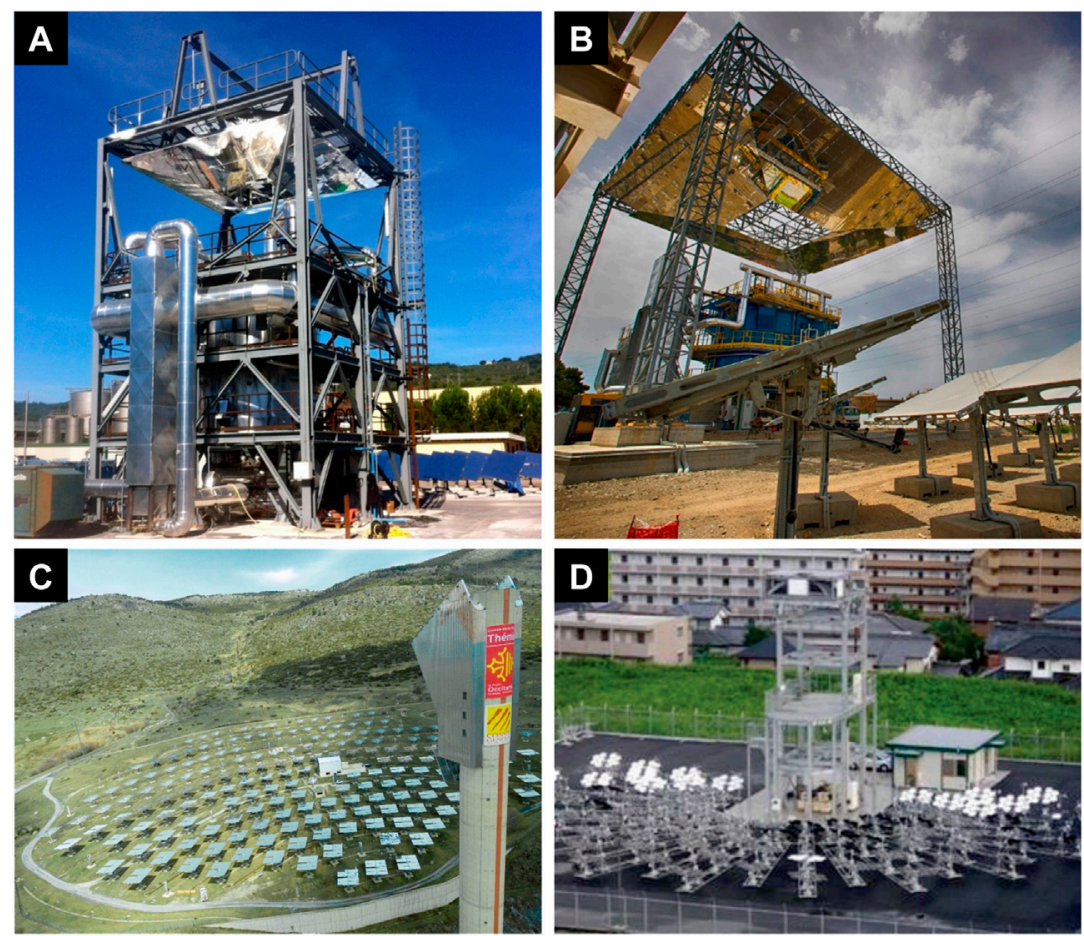

FIGURE 9| Photographs of fluidized bed installations for CSP with energy storage. (A) Indirectly irradiated STEM ${ }^{\circledR}$ Solar Thermo-Electric Magaldi (Magaldi, 2020); (B) Directly irradiated STEM ${ }^{\circledR}$ Solar Thermo-Electric Magaldi (Magaldi, 2020); (C) Themis solar tower to be revamped according to the fluidized particle-in-tube concept (reprinted from Ferriere et al. (2019) with the permission of AIP Publishing); (D) Window-type internally circulating fluidized bed receiver at Miyazaki (reprinted from Kodama et al. (2017b) with the permission of AIP Publishing).

FB (Flamant, 1982; Bachovchin et al., 1983; Megahed et al., 1988; Haddad and Elsayed, 1988; Koenigsdorff and Kienzle, 1991; Sasse and Ingel, 1993; Werther et al., 1994; Baud et al., 2012; Chirone et al., 2013; Flamant et al., 2013; Ma et al., 2014; Marti et al., 2015; Reyes-Belmonte et al., 2019; Farsi and Dincer, 2019; Díaz-Heras et al., 2020a). The extension of these concepts to the industrial scale is a matter still deserving thoughtful investigation. However, early operation of pilot and demonstration installations is documented. Figure 9 reports the beam-down $150 \mathrm{~kW}_{\text {th }}$ indirectly irradiated (Chirone et al., 2013) and $2 \mathrm{MW}_{\text {th }}$ directly irradiated (Magaldi, 2020) stationary compartmented dense FB (Type D), the beam-down window-type $100 \mathrm{~kW}_{\text {th }}$ internally circulating FB at Miyazaki (Type F) and a new installation based on the fluidized particle-in-tube concept (Type E) and on the revamping of the Themis Tower (Ferriere et al., 2019; Le Gal et al., 2019) to demonstrate the technology in a relevant environment $(\mathrm{TRL}=6)$ with a satisfying thermal throughput $\left(4 \mathrm{MW}_{\mathrm{th}}\right)$.

\section{Solar-Driven Looping Cycles}

The potential of FBs as multiphase chemical reactors is widely recognized in solar-driven solids looping cycles entailing reversible chemical reactions. Hydration/dehydration (Schmidt et al., 2014; Sakellariou et al., 2015; Angerer et al., 2018), calcination/carbonation (André and Abanades, 2017; Tregambi et al., 2019b; Tregambi et al., 2019c; Yan et al., 2020), oxidation/ reduction of metal hydroxides, carbonates and oxides (Block et al., 2014; Haseli et al., 2017; Singh et al., 2017; Wu et al., 2018; Yan et al., 2020) are being considered in solar-assisted chemical processing of solids. These reactions require an intimate gas-solid contact and thorough temperature control, hence FB reactors/receivers are natural candidates for their implementation. It must be pointed out that, even if solardriven looping cycles would be most conveniently carried out in dual interconnected FB reactors, much like conventional nonsolar looping processes, their experimental assessment has been carried out to date only in ordinary bubbling FB reactors (Type A), by separate characterization of each stage. Extension to realistic operation of dual bed reactors is needed to fully assess the technology.

Calcium carbonation/calcination $\left(\mathrm{CaCO}_{3}=\mathrm{CaO}+\mathrm{CO}_{2}\right)$ is a reversible reaction characterized by fairly large reaction heat $\left(\Delta H^{\circ} \approx 178 \mathrm{~kJ} \mathrm{~mol}^{-1}\right)$ on which conventional CaL for CCSU is based. Coupling CaL with CSP has been considered for both CCSU (Matthews and Lipiński, 2012; Coppola et al., 2013; Reich et al., 2014; Zhang and Liu, 2014; Tregambi et al., 2015; Zhai et al., 2016) and TCES (Edwards and Materić, 2012; Alovisio et al., 2017; Ortiz et al., 2018; Sarrión et al., 2018; Tregambi et al., 2019b; Sánchez Jiménez et al., 2019; Bailera et al., 2020). The conventional CaL concept for CCSU is based on the alternated temperature-swing uptake and release of $\mathrm{CO}_{2}$ by a calcium-based sorbent (Blamey et al., 2010; Erans et al., 2016). In the carbonator, a stream of $\mathrm{CaO}$ sorbent captures $\mathrm{CO}_{2}$ at around $650-750^{\circ} \mathrm{C}$ (exothermic 
carbonation). The carbonator issues a flue gas depleted in $\mathrm{CO}_{2}$, together with carbonated sorbent solid stream (a mixture of $\mathrm{CaCO}_{3}$ and $\mathrm{CaO}$ ). The carbonated sorbent is sent to the calciner where the endothermic reverse calcination (sorbent regeneration) is carried out at temperatures of $900^{\circ} \mathrm{C}$ and above with emission of a $\mathrm{CO}_{2}$-rich flue gas. The heat required to sustain the calcination endothermicity can be supplied by burning an auxilirary fuel in an oxy-firing mode, thus allowing to avoid the dilution of the gaseous product stream from the calciner, that is required to be rich in $\mathrm{CO}_{2}$. This entails the coupling of the calcium looping plant with an Air Separation Unit (ASU) to provide the feeding of an oxygen-rich stream to the calciner. Calcium looping is most typically performed in a dual interconnected FB reactor configuration, for easy solid transfer from one reactor to the other and to work in a suitable environment for the progress of the reactions. The sorbent $\mathrm{CO}_{2}$ uptake rate and capacity decay over iterated looping due to sintering and/or possible reaction of the sorbent with acidic gases, like $\mathrm{SO}_{2}$ (Coppola et al., 2019a). Moreover, sorbent attrition and fragmentation affect the particle size distribution (and residence time distribution) contributing to calcium losses as elutriable fines (Su et al., 2018; Coppola et al., 2019b). The management of the CaL cycle thus requires a continuous make-up of a fresh limestone stream, so to take into account and compensate deactivation and elutriation phenomena.

CSP-CaL integration may be based on different design and operating conditions depending on whether it is primarily targeted to CCSU or to TCES (Figure 10). When CCSU is the primary goal, operating conditions of the calciner resemble those of conventional $\mathrm{CaL}$ driven by oxy-combustion (temperature ca. $940^{\circ} \mathrm{C}, 70 \%{ }_{\mathrm{v}} \mathrm{CO}_{2}$ ). In this case, CSP plays the role of energy supplier to the calciner, so that oxy-combustion and the associated complexity of ASU can be avoided. The process may be designed so as to work for $24 \mathrm{~h}$ a day, as reported by Tregambi et al. (Tregambi et al., 2015; Tregambi et al., 2019b), by proper management of fluxes and inventories of sorbent in either the calcined or the carbonated stage. Seasonal and/ or daily TCES strategies may be implemented (Tregambi et al., 2021). A performance assessment of this scheme was carried out by model computations showing that as much as $80 \%$ of the thermal input from CSP to the calciner can be recovered at the carbonator as valuable thermal power (Tregambi et al., 2015). The high-purity $\mathrm{CO}_{2}$ stream from CSP-CaL can be reacted with $\mathrm{H}_{2}$ obtained from water electrolysis (driven by $\mathrm{PV}$ or excess renewable energy), to eventually produce $\mathrm{CH}_{4}$ (Tregambi et al., 2021).

When TCES is the primary goal of CSP-CaL integration (Tregambi et al., 2019b), the calcination process can be operated at lower temperature (e.g., $850^{\circ} \mathrm{C}$ ) with respect to the CCSU case, thus limiting sintering of sorbent particles and reducing sorbent deactivation upon cycling. Carbonation is operated using exhaust gas from $\mathrm{CO}_{2}$-emitting industrial sectors, e.g. power plants burning fossil fuels or plants for cement/steel production. Calcination, sustained by CSP, is performed with air as carrier/fluidizing gas, i.e. under conditions with low $\mathrm{CO}_{2}$ concentration.

Tregambi et al. (2019b) report a detailed comparison of the performance of solar-driven CaL in either the CCSU or the TCES variants. Energy storage densities are within $960-1,130 \mathrm{MJ} \mathrm{m}^{-3}$ (TCES) and 780-960 $\mathrm{MJ} \mathrm{m}^{-3}$ (CCSU). The limited reduction of energy storage density in the CCSU option is compensated by the reduction of the overall carbon footprint of the integrated process. The reported values of energy storage densities are slightly larger than those obtained by commercial molten salts. Furthermore, CaL ensures better long term storage stability and higher temperature at which to exchange stored energy.

Tregambi et al. (2018a) investigated fundamental aspects of solardriven $\mathrm{CaL}$ in a FB in a directly irradiated lab-scale FB comparing solar-driven and conventional CaL conditions. Local and occasionally high peak temperatures suffered by sorbent in solardriven $\mathrm{CaL}$ may bring about noticeable thermal sintering, hence sorbent deactivation, as inferred by microstructural characterization. Controlling radiative flux and energy balance at the irradiated footprint in directly irradiated FB is essential to prevent deadburning of bed material. These results were further confirmed by Tregambi et al. (2019b), who compared the reactivity of limestone sorbent in either the CCSU or the TCES version of solar-driven CaL. TCES conditions determine a more reactive material, due to the development of advantageous microstructural properties-larger specific surface area and smaller mean pore size-which reflect the lower calcination temperature and $\mathrm{CO}_{2}$ concentration.

Nikulshina and Steinfeld (2009) and Nikulshina et al. (2009) investigated $\mathrm{CO}_{2}$ capture from ambient air in a directly irradiated lab-scale FB reactor under simulated solar irradiation. Reactive $\mathrm{Ca}(\mathrm{OH})_{2}\left(11 \mu \mathrm{m}\right.$, Fluka ${ }^{\circledR}$ reagent $)$ was mixed with inert $\mathrm{SiO}_{2}$ $(229 \mu \mathrm{m})$ particles to improve fluidization behavior of the otherwise cohesive powder (overall $\mathrm{CaO}$ fraction $3 \%_{\mathrm{wt}}$ ). Carbonation was performed using synthetic air, with a $\mathrm{CO}_{2}$ content of $500 \mathrm{ppm}$ and a steam fraction up to $17 \%$ (balance $\mathrm{Ar}$ ), at a process temperature of $365-400^{\circ} \mathrm{C}$. The presence of $\mathrm{H}_{2} \mathrm{O}$ during carbonation improves sorbent reactivity. Calcination was performed at $800-875^{\circ} \mathrm{C}$. $\mathrm{CO}_{2}$ concentration in the exhaust was reduced down to $1 \mathrm{ppm}$. A carbonation degree of $60-70 \%$ was obtained without appreciable sorbent deactivation, thanks to the positive influence of steam on sintering.

Padula et al. (2021) model the CSP-CaL integration within the DIFBAR scheme (see The Autothermal Fluidized Bed Reactor) for the design of a "thermochemical battery". The potential of the effective DIFBAR autothermal operation mode is demonstrated. The optimal operation temperature and efficiency during the charge and the discharge steps of the thermochemical battery are achieved.

Raganati et al. (2020) report on a special implementation of CaL for TCES based on a sound-assisted FB to process fine sorbent material $\left(d_{\text {Sauter }}=4 \mu \mathrm{m}\right)$ and improve reactivity over cycling (see Pulsed and Sound-Assisted Fluidization). Process conditions were similar to those investigated by Chacartegui et al. (2016) and Benitez-Guerrero et al. (2017): carbonation at $850^{\circ} \mathrm{C}$ and $70 \% \mathrm{CO}_{2}$, calcination at $750^{\circ} \mathrm{C}$ under inert atmosphere. Sorbent reactivity along cycling was far higher than that obtained with coarser particles (Benitez-Guerrero et al., 2017), with a mean carbonation degree at the $20^{\text {th }}$ reaction cycle of about $60 \%$ (vs. $20 \%$ for coarse particles). The very promising results obtained at the bench scale challenge the non-trivial scale-up of the soundassisted FB to the industrial scale.

Ma et al. (2020a) performed CaL experiments for TCES in a small FB (32 mm ID, electric ovens as heaters) focusing on both attrition performance and energy storage density. Best results 

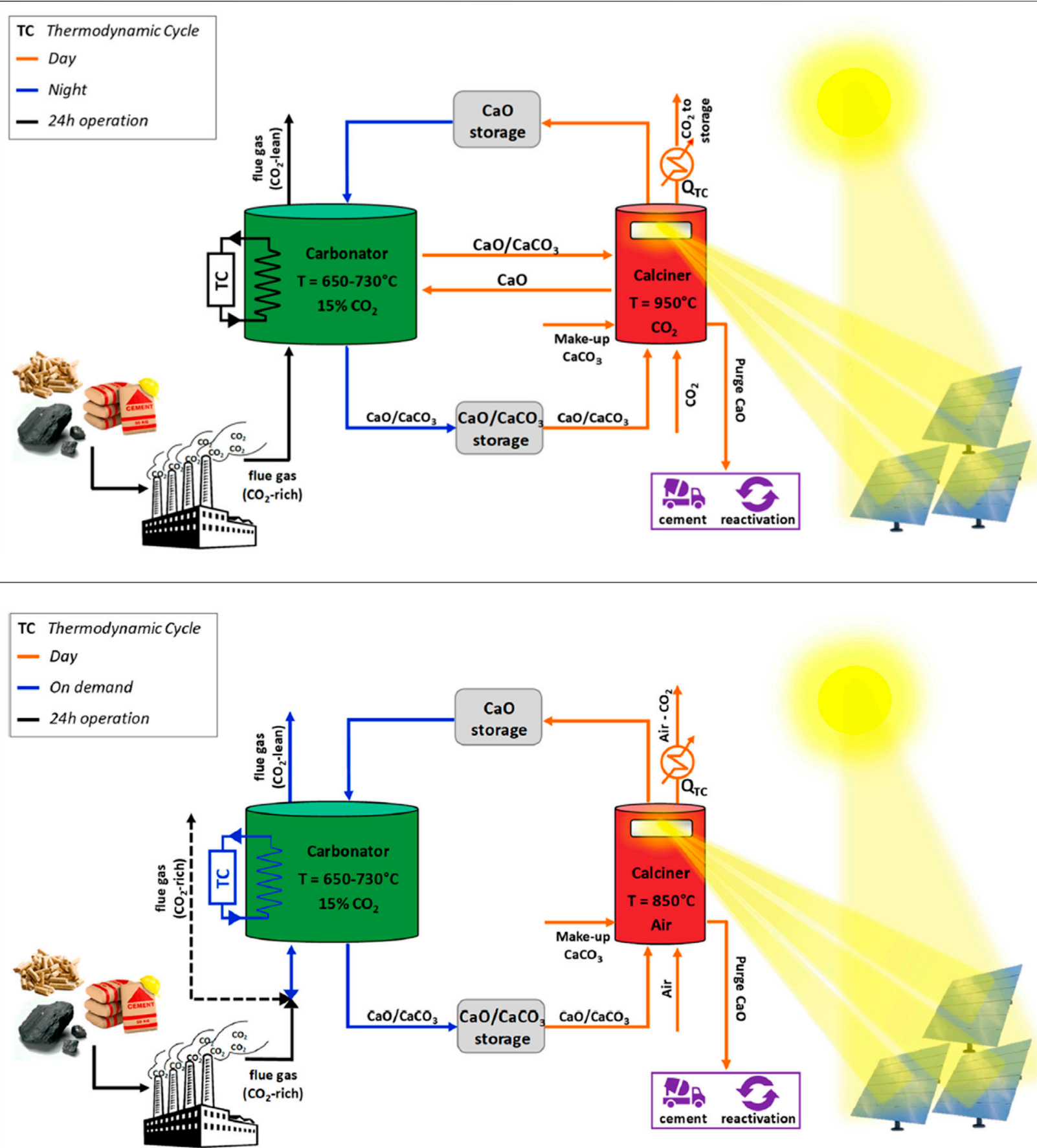

FIGURE 10 | Outline of the integrated CSP-CaL process for CCSU (A) and TCES (B) (reprinted/adapted with permission from Tregambi et al. (2019b). Copyright (2019) American Chemical Society).

were achieved when working at $100 \% \mathrm{CO}_{2}$ and $850-870^{\circ} \mathrm{C}$ for carbonation, and $100 \% \mathrm{~N}_{2}$ at $800-850^{\circ} \mathrm{C}$ for calcination, using limestone within $125-180 \mu \mathrm{m}$ as reactant. After 20 cycles, the Authors report a mean carbonation degree of 50\%, an energy storage density of $1,500 \mathrm{~kJ} \mathrm{~kg}^{-1}$, and a $3.5 \%$ decrease in the mean Sauter diameter.

Calcination/carbonation of $\mathrm{SrCO}_{3}$ was also considered for TCES. This reversible reaction features a higher equilibrium temperature with respect to $\mathrm{CaCO}_{3} / \mathrm{CaO}$, but is affected by severe sintering and/or agglomeration (André and Abanades, 2017). Ammendola et al. (2020) tested synthetic $\mathrm{Al}_{2} \mathrm{O}_{3}$-stabilized composite materials to inhibit sintering in a lab-scale electrically heated FB. Calcination and carbonation of 200-600 $\mu \mathrm{m}$ particles were performed at $1,000^{\circ} \mathrm{C}$, with a gas feeding containing $50 \%$ $\mathrm{CO}_{2}$ during carbonation and pure $\mathrm{N}_{2}$ during calcination. The composite sorbents performed well, whereas pure $\mathrm{SrCO}_{3}$ sorbent 
underwent rapid bed agglomeration. Best performance in terms of carbonation degree (nearly $30 \%$ over the last 7-8 reaction cycles) and energy storage density (about $400 \mathrm{~kJ} \mathrm{~kg}^{-1}$ based on latent heat only) was achieved with an $\mathrm{Al}_{2} \mathrm{O}_{3}$ fraction of $23 \%$.

Flegkas et al. (2018) performed a modeling study on the use of FBs for TCES using the reaction couple $\mathrm{MgO} / \mathrm{Mg}(\mathrm{OH})_{2}$. The supply of steam was identified as a potential drawback of the process, as it consumes a relevant share of the energy released during the exothermic step.

$\mathrm{CaO}$ hydration/dehydration has been frequently considered for TCES. This process was experimentally assessed by Pardo et al. (2014) in a lab-scale electrically heated FB reactor (Type A, Table 1). Fine $\mathrm{Ca}(\mathrm{OH})_{2}$ particles (mean diameter of $4 \mu \mathrm{m}$ ) were mixed with $70 \%$ wt of coarser $\mathrm{Al}_{2} \mathrm{O}_{3}$ particles (mean diameter of $172 \mu \mathrm{m}$ ) to enable fluidization. Dehydration was performed at a wall temperature of $480^{\circ} \mathrm{C}$, using $\mathrm{N}_{2}$ as fluidizing gas, while hydration at a wall temperature of $350^{\circ} \mathrm{C}$, with a water partial pressure of $31.1 \mathrm{kPa}$. The reactivity of the material was fairly constant over fifty cycles, with a conversion degree of about $90 \%$. However, accumulation of part of the reactive material on the top of reactor and clogging of the filters due to cake formation was observed. Energy storage density is about $562 \mathrm{MJ} \mathrm{m}^{-3}$ if the reactive material can be separated from the inert $\mathrm{Al}_{2} \mathrm{O}_{3}$, dropping to nearly $216 \mathrm{MJ} \mathrm{m}^{-3}$ without separation. This study was eventually extended by Criado et al. (2017) with the aim of improving the overall TCES performance. The reactor was operated as bubbling $\mathrm{FB}$ in the range of $0.3-0.53 \mathrm{~m} \mathrm{~s}^{-1}$ gas superficial velocity. Dehydration was performed at $450-500^{\circ} \mathrm{C}$, with an inlet $\mathrm{H}_{2} \mathrm{O}$ fraction between 0 and 0.08 . Hydration was performed at $390-460^{\circ} \mathrm{C}$ with an inlet $\mathrm{H}_{2} \mathrm{O}$ fraction of $0.57-0.84$. The sorbent was limestone calcined at the fairly high temperature of $1,000^{\circ} \mathrm{C}$ to improve the mechanical performance and avoid the use of a mechanical support. A fairly small sorbent conversion degree (20-40\%) was obtained, attributed to the severe calcination conditions. Experimental tests with similar process conditions were also performed by Rougé et al. (2017) in a FB reactor (Type A) equipped with hoppers and screw feeders for continuous operation. Criado et al. (2014) developed a model of a TCES process based on $\mathrm{CaO}$ hydration/dehydration, embodying separate storage vessels for $\mathrm{CaO}$ and $\mathrm{Ca}(\mathrm{OH})_{2}$, and a single circulating FB reactor alternating between energy collection and retrieval. Hydration was performed at $470^{\circ} \mathrm{C}$ with pure steam, dehydration at $540^{\circ} \mathrm{C}$. A mean conversion degree of $60 \%$ was considered, in order to account for the presence of an inert support enhancing the mechanical stability of the reactive material. Model computations foresaw an energy storage density of $936 \mathrm{MJ} \mathrm{m}^{-3}$.

\section{Solar-Driven Production of Fuels}

\section{$\mathrm{H}_{2} \mathrm{O} / \mathrm{CO}_{2}$ Splitting}

One of the most ambitious targets of CSP technologies is the production of "green" $\mathrm{H}_{2}$ and $\mathrm{CO}$ from two-step $\mathrm{H}_{2} \mathrm{O} / \mathrm{CO}_{2}$ splitting cycles. In this process, a metal oxide is thermally reduced at high temperature following an endothermic chemical reaction with inherent $\mathrm{O}_{2}$ release. CSP supplies the reaction heat, as well as that needed to establish the high temperatures required by the reaction thermodynamics. The reduced metal oxide is then oxidized by $\mathrm{H}_{2} \mathrm{O} / \mathrm{CO}_{2}$, with inherent production of $\mathrm{H}_{2} / \mathrm{CO}$. Re-oxidation, slightly exothermic, is carried out at lower temperature. The two-step scheme brings about a consistent reduction of the operating temperature compared to direct thermolysis. Moreover, $\mathrm{H}_{2} / \mathrm{CO}$ and $\mathrm{O}_{2}$ are released in different environments, preventing the formation of potentially explosive mixtures. Nevertheless, temperatures required to accomplish thermal reduction typically exceed $1,000-1,200^{\circ} \mathrm{C}$. Moreover, it is imperative to establish reaction environments free of $\mathrm{O}_{2}$ and/or under vacuum. The search for suitable metal oxides for two-step splitting cycles is a challenging task. Pure metal oxides, volatile vs. non-volatile compounds, solid solution of different oxides, supported and unsupported materials have been investigated. The topic has been extensively surveyed in the literature (Kodama, 2003; Kodama and Gokon, 2007; Lu et al., 2019).

The ambitious concept of two-step water splitting cycles calls for careful design of multiphase reactors for performing either step of the process (Kodama et al., 2017a). FBs have been widely investigated as combined solar receiver/reactors, on account of their well-established features as multiphase chemical reactors and the possibility to establish the fairly high temperatures required by the thermal reduction step.

Kodama and coworkers were among the first to investigate the use of FB reactors to accomplish $\mathrm{H}_{2} \mathrm{O}$ splitting (Gokon et al., 2006; Gokon et al., 2008; Kodama et al., 2008). The reactive material was a ferrite solid solution $\left(\mathrm{NiFe}_{2} \mathrm{O}_{4}\right)$ supported on $\mathrm{ZrO}_{2}$ carrier, with ferrite content of about $20 \%{ }_{\text {wt }}$. Thermal reduction tests were performed in a special design of directly irradiated FB (Type F, Table 1), to improve collection and to promote effective axial transport of the incident radiation. Particles in the size range of $100-200 \mu \mathrm{m}$ and $200-1,000 \mu \mathrm{m}$ were used. Experimental results confirmed the effectiveness of internal recirculation to equalize temperature along the reactor with improved conversion of the reactive ferrite. These findings were confirmed in experiments performed in a stainless steel reactor (45 mm ID) equipped with a $17 \mathrm{~mm}$ ID draft tube for internal circulation. Reduction of ferrite reached $44 \%$ after $30 \mathrm{~min}$ of irradiation at $1.2 \mathrm{~kW}_{\text {th }}$, without appreciable sintering and/or agglomeration. $\mathrm{H}_{2} \mathrm{O}$ decomposition tests were successfully performed in a dedicated packed bed reactor without any pretreatment on the material withdrawn from the FB. Experiments with an improved solar simulator ( $2.6 \mathrm{~kW}_{\text {th }}$ input power, $2,400 \mathrm{~kW} \mathrm{~m}^{-2}$ peak flux) were later performed by Gokon et al. (2011). Heating of the system was accomplished by concentrated radiative flux only and both thermal reduction and $\mathrm{H}_{2} \mathrm{O}$ decomposition were performed in the same FB. During thermal reduction, the solar simulator was operated at full power for $15 \mathrm{~min}$. Surface bed temperature was $1,500-1,600^{\circ} \mathrm{C}$ in the draft tube and $1,100-1,250^{\circ} \mathrm{C}$ in the annular region. Water decomposition was performed at about $1.6 \mathrm{~kW}_{\text {th }}$ and lasted from 10 to $92 \mathrm{~min}$. Maximum ferrite conversion was $40 \%$. The solar energy-to- $\mathrm{H}_{2}$ yield, on an energy basis, was less than $1 \%$, due to insufficient thermal insulation and slow kinetics during re-oxidation. Despite the small yield, Kodama and coworkers first demonstrated that $\mathrm{H}_{2} \mathrm{O}$ splitting can be performed in a single $\mathrm{FB}$ reactor by alternating process conditions without sintering/agglomeration of the bed 
material. Results obtained with unsupported $\mathrm{NiFe}_{2} \mathrm{O}_{4}$ ferrite were not satisfactory.

More recently, Kodama et al. (2018) investigated $\mathrm{H}_{2} \mathrm{O}$ splitting in $\mathrm{FB}$ using $\mathrm{CeO}_{2}$, one among the most promising materials for two-step water splitting. Experiments were performed in a directly irradiated FB of $16 \mathrm{~cm}$ diameter, aspect ratio of 1 , operated with uneven gas distribution to promote internal circulation of the fluidized solids (Type F, Table 1). A solar simulator with an input power of $30 \mathrm{~kW}_{\text {th }}$ was used. Thanks to the direct irradiation profile, bed temperature reached $1,400-1,500^{\circ} \mathrm{C}$ but wall temperature never exceeded $1,200^{\circ} \mathrm{C}$, thus preventing damage to the reactor. Only very preliminary results are documented, from which an average nonstoichiometric factor of $\mathrm{CeO}_{2}$ of about 0.02 was obtained. An on-sun experimental campaign using ceria has been recently undertaken (Kodama et al., 2019) on a scaled up version of the $\mathrm{FB}$ reactor coupled with a $100 \mathrm{~kW}_{\text {th }}$ beam-down solar concentrating system with a secondary elliptical reflector. Preliminary indications, providing evidence of $\mathrm{O}_{2}$ release and $\mathrm{H}_{2}$ production, have been reported so far.

Modeling of $\mathrm{CO}_{2}$ splitting in a double-loop $\mathrm{FB}$ using $\mathrm{CeO}_{2}$ clustered nanoparticles, so as to maximize the surface area, has been reported by Milanese et al. (2017a). The kinetics of $\mathrm{CeO}_{2}$ reduction was assessed by tests in TGA. Altogether, a maximum ideal efficiency of about $63 \%$ was estimated, defined as ratio between the Lower Heating Value (LHV) of the produced CO and the input solar energy. The same Authors performed an in-depth analysis of the relevant configuration of the proposed system (Milanese et al., 2017b), highlighting the importance of parameters such as mean residence time, solar concentration ratio, cross-sectional area of the FB. A yearly averaged global efficiency of about $30 \%$ was estimated for an optimized configuration.

Hoskins et al. (2019) demonstrated on-sun production of $\mathrm{H}_{2}$ using hercynite $\left(\mathrm{FeAl}_{2} \mathrm{O}_{4}\right)$ as reactive material. Experiments were performed using two FBs, indirectly heated, located within a single cavity receiver and heated by a $10 \mathrm{~kW}$ solar furnace. The reactors were Type A bubbling FBs in a cylindrical SiC vessel, $2.54 \mathrm{~cm}$ OD and $35.6 \mathrm{~cm}$ high. Each reactor was operated with an inventory of about $40 \mathrm{~g}$ of hercynite (average particle size of $400 \mu \mathrm{m})$. During the tests, the bulk FB temperature was kept at about $1,000^{\circ} \mathrm{C}$, the cavity between the two FBs at about $1,300^{\circ} \mathrm{C}$. Productivity of $\mathrm{H}_{2}$ was $547-597 \mu \mathrm{mol} \mathrm{H}_{2} \mathrm{~g}^{-1}$. Hercynite was stable over multiple days of on-sun redox testing, as highlighted by XRD analyses. It was pointed out that cloudy weather conditions strongly affect the reactor temperature, claiming for the need of advanced control systems to achieve stationary $\mathrm{H}_{2}$ production.

He et al. (2014) proposed a different process for liquid fuels and $\mathrm{H}_{2}$ production, with some analogies to the conventional $\mathrm{H}_{2} \mathrm{O}$ splitting scheme described so far. Reduction of the metal oxide is performed with $\mathrm{CH}_{4}$ to lower the process temperature from about 1,400 to $900^{\circ} \mathrm{C}$ and produce syngas. The reduced carrier is then reacted with $\mathrm{H}_{2} \mathrm{O}$ to obtain $\mathrm{H}_{2}$ as in conventional splitting cycles. Syngas from $\mathrm{CH}_{4}$ conversion may be exploited by Fischer-Tropsch process to produce liquid hydrocarbons, further refined into naphtha and diesel. $\mathrm{H}_{2}$ from water splitting represents a final product upon compression/ purification. Part of it is used in the reformer to upgrade the quality of naphtha/diesel. Lanthanum Strontium Ferrite (LSF)supported $\mathrm{Fe}_{3} \mathrm{O}_{4}$ is investigated as reactive material and its performance was tested under fixed and FB conditions, using an electrically heated lab-scale tubular reactor. Small amounts of $\mathrm{CO}$ and $\mathrm{CO}_{2}$ were detected during the early stage of $\mathrm{H}_{2} \mathrm{O}$ splitting, arising from gasification of the coke deposited on the oxygen carrier during the previous reduction. The experimental campaign was complemented by process simulation yielding an overall process efficiency of nearly $64 \%$ when considering both methane and solar energy inputs.

Research on thermochemical splitting cycles in FB reactors is only at early stage. The use of special designs is imperative to achieve the large temperature values dictated by thermodynamics and kinetics constrains, while accomplishing effective recovery of sensible heat between the high and low temperature reaction steps. This requirement has stimulated the development of special designs entailing autothermal reaction schemes (Type J, Table 1) (Tregambi et al., 2020a; Tregambi et al., 2020b).

\section{Solar-Driven Gasification}

Solar gasification is a promising route for thermochemical conversion of carbon-based materials (coal, coke, biomass) (Puig-Arnavat et al., 2013; Troiano et al., 2017a; Gokon et al., 2019) and the most investigated process for solar fuels production when compared to pyrolysis and torrefaction (Hopkins et al., 1984; Berber and Fletcher, 1988; Lédé, 1999; Tregambi et al., 2019d). Solar gasification represents an efficient path to store solar energy as a chemical vector, with upgraded energy content (approximately $\sim 45 \%$ ) of the syngas compared to the carbon feedstock, improving the dispatchability of the initial resource. A chemical storage efficiency may be defined as the ratio between the incremental LHV of the syngas with respect to the original feedstock, and the input solar energy. Among the benefits of the solar thermochemical process, absence of partial combustion of the feedstock, no contamination from combustion by-products and no need for upstream air separation are highlighted. In addition, costs for cleaning and separation of downstream gas are reduced (Gregg et al., 1980; Lédé, 1999; Puig-Arnavat et al., 2013; Gokon et al., 2019). The use of highly concentrated solar power enables higher gasification temperatures $\left(>1,200^{\circ} \mathrm{C}\right)$, hence faster reaction kinetics, improved syngas quality and reduced tar content (Troiano et al., 2020b). Key issues associated with solar gasification are related to the management of the intermittent nature of solar radiation (Puig-Arnavat et al., 2013). Even though the association of CSP and coal/biomass gasification has been frequently suggested, relatively few projects have been effectively reported, mainly at fundamental and laboratory levels. Solar gasifiers of solid feedstock are typically designed to operate at temperatures around $1,300 \mathrm{~K}$ and can be classified into indirectly and directly irradiated reactors.

The superior performance of FBs for solar gasification, as compared with competing fixed, packed, and moving bed reactors, has been highlighted by Nathan et al. (2017). FB solar gasifiers are mostly directly irradiated (Kodama et al., 
2017a). Taylor et al. (1983) were among the first to demonstrate the feasibility of solar-driven $\mathrm{CO}_{2}$ gasification of carbonaceous materials (coconut charcoal particles) in a Type A FB. The reactor consisted of a vertical $5 \mathrm{~cm}$ ID silica-glass tube located at the focus of a $2 \mathrm{~kW}$ solar furnace in a beam-down arrangement. A maximum chemical storage efficiency of $10 \%$ was obtained with $30 \% \mathrm{CO}_{2}$ conversion at a solar power of about $1.1 \mathrm{~kW}$. Murray and Fletcher (1994) investigated steam gasification of cellulose in different types of ordinary (Type A) solar FB reactors, both directly (quartz) and indirectly (stainless steel) irradiated. Müller et al. (2003) investigated steam coal gasification using a quartz tubular reactor with Type A FB and directly irradiated by the ETH's high flux solar simulator (Hirsch et al., 2003). The total incident power was $2.6 \mathrm{~kW}$, while the operating temperature was in the range $1,000-1,600 \mathrm{~K}$. The tests were carried out using activated charcoal pellets. A syngas with equimolar amount of $\mathrm{H}_{2}$ and $\mathrm{CO}$, and a low $(<5 \%) \mathrm{CO}_{2}$ content, was produced above $1,400 \mathrm{~K}$. Its LHV was $530 \mathrm{~kJ} \mathrm{~mol}^{-1}$, with an excess calorific value of $34 \%$ with respect to the original feedstock. Steam gasification of activated charcoal was tested by von Zedtwitz and Steinfeld (2005) in a quartz reactor under radiative flux exceeding $4,250 \mathrm{~kW} \mathrm{~m}^{-2}$ supplied by the ETH's high flux simulator. Again, above $1,450 \mathrm{~K}$, the syngas composition consisted of an equimolar mixture of $\mathrm{H}_{2}$ and $\mathrm{CO}$, in agreement with thermodynamic equilibrium calculations. The quality of the syngas was remarkably superior to that typical for reactors operated in autothermal conditions, with the additional benefit of upgraded calorific value.

Kodama et al. (2002) studied the FB gasification with $\mathrm{CO}_{2}$ of Australian bituminous coal. The experimental setup consisted of a directly irradiated Type A quartz FB reactor using Xe-arc lamp concentrators and peak flux density irradiation as large as $1,270 \mathrm{~kW} \mathrm{~m}^{-2}$. A maximum energy storage efficiency of $8 \%$ was obtained. The performance was affected by large heat losses related to the small size of the reactor. A beam-down arrangement was used in a later investigation (Kodama et al., 2010) of $\mathrm{CO}_{2}$ gasification of coal coke using a $6 \mathrm{~kW}$ Xe-arc lamp sun simulator as energy source. A Type-A stainless steel windowed $62.3 \mathrm{~mm}$ ID FB reactor was used. A maximum energy storage efficiency of $14 \%$ was reported by irradiating the FB with a power input of about $1.1 \mathrm{~kW}$. The analysis of the temperature distribution suggested that the reaction zone was confined to the upper part of the bed and the radiative power was poorly transferred to the lower bed (Gordillo and Belghit, 2011). This finding stimulated Kodama et al. to develop the windowed FB reactor with internal circulation (Kodama et al., 2008; Gokon et al., 2012), whose features are reported in The InternalCirculation Fluidized Bed Solar Reactor (Table 1, Type F). The reactor was exposed to a $6 \mathrm{~kW}$ Xe-arc lamp with a mean flux of $750 \mathrm{~kW} \mathrm{~m}^{-2}$. The gasification performance compared very favourably with that of a conventional $\mathrm{FB}$ reactor, under the same operating conditions. The carbon conversion degree reached a value of $X_{C}=73 \%$ for the internally circulating FB reactor, vs. $X_{C}=40 \%$ for the conventional reactor. The chemical storage efficiency was around $12 \%$. Early results paved the way to improved design and operation of the gasifier (Gokon et al., 2014; Gokon et al., 2015) that involved the steam generator and the enhancement of heat transfer in the bed via addition of inert quartz sand particles. Coke conversion of about $93 \%$ and maximum energy storage efficiency of $13 \%$ were obtained. Recent developments at Niigata University include the development of a beam-down sun-simulator with lighting provided by three $7 \mathrm{~kW}$ e Xe-lights and a novel design of the windowed $5 \mathrm{~kW}_{\text {th }}$ internally circulating $\mathrm{FB}$ reactor. Test programs were specifically aimed at characterizing the variation in temperature and its distribution within the bed, rates of gasification for coal coke, conversion of $\mathrm{C}$ and chemical storage efficiencies (Bellan et al., 2017, Bellan et al., 2018a; Bellan et al., 2018b; Bellan et al., 2018c; Bellan et al., 2019a; Bellan et al., 2019b; Gokon et al., 2019). The important role of the volume fraction of coal-coke in the FB of quartz sand was highlighted. At increasing volume fraction of coal coke, gas production rate increased, but operation became unstable, due to excess endothermic reaction along gasification. Chemical storage efficiency in the order of $11.0-13.2 \%$ and carbon conversion degrees of $60-80 \%$ were reported.

Muroyama et al. (Muroyama et al., 2014; Muroyama et al., 2018) report on the development of a $1.5 \mathrm{~kW}_{\text {th }}$ hybrid solar/ autothermal Type A FB gasifier, tested in a $6 \mathrm{~kW}_{\text {th }}$ high-flux solar simulator. The indirectly irradiated gasifier consisted of a cavity made of Buster M-35 (Zircar Zirconia) blocks. The front block contained a conical aperture with $40 \mathrm{~mm}$ diameter. An absorber tube made of sintered $\mathrm{SiC}$ was located inside the cavity and Monte Carlo ray-tracing analysis was performed to optimize absorption of the concentrated light. The bulk of the bed consisted of fused $\mathrm{Al}_{2} \mathrm{O}_{3}$ granules $(0.3-0.6 \mathrm{~mm})$. Gasification of granular activated charcoal from peat or North Dakota lignite coal was tested by varying $\mathrm{H}_{2} \mathrm{O}: \mathrm{C}(1.10-2.32)$ and $\mathrm{O}_{2}: \mathrm{C}(0-0.33)$ ratios. The impact of $\mathrm{O}_{2}: \mathrm{C}$ and $\mathrm{H}_{2} \mathrm{O}: \mathrm{C}$ ratios and the closely associated balance between allothermal (solar-driven) and autothermal gasification on carbon conversion and syngas properties were analyzed, showing how $\mathrm{H}_{2} \mathrm{O}$ and $\mathrm{O}_{2}$ feeding must be adjusted depending on solar power availability and desired $\mathrm{H}_{2}$ : $\mathrm{CO}$ ratio. Carbon conversions of nearly $80 \%$ were observed, and maximum cold gas ratios and chemical storage efficiencies were 1.16 and $22.1 \%$, respectively.

Li et al. (2020) reported on steam gasification of sewage sludge in an indirectly irradiated Type A FB solar gasifier with a co-axial tubular configuration. Kinetic data for sewage sludge pyrolysis were obtained in lab-scale FB reactor and used in gasifier models (dynamic two-phase and pseudo one-dimensional), validated against experimental data. The influence of concentrated solar irradiance, composition of the gasifying agent and spatial distribution of solar flux on the process performance was analyzed, in terms of chemical storage efficiency and $\mathrm{H}_{2}$ yield.

Solar spouted bed reactors have been recently numerically and experimentally investigated for biomass gasification (Boujjat et al., 2020; Ma et al., 2020b). In particular, a design of solar reactor basing on the conical spouted bed reactor was developed at CNRS-PROMES laboratory (Table 1, Type B) and applied to biomass gasification (Bellouard et al., 2017; Chuayboon and Abanades, 2020). This conical spouted bed is designed to ensure intimate gas-solid contact during thermal treatment of biomass particles of different size, good solids mixing, long solids 
residence times. The reactor may be operated either in the direct or in the indirect irradiation mode with continuous feeding. A $1.5 \mathrm{~kW}_{\text {th }}$ prototype based on the spouted bed design was tested for the continuous solar gasification of wood biomass in the directly irradiated configuration (Bellouard et al., 2017; Boujjat et al., 2019b; Bellouard et al., 2019; Boujjat et al., 2020). The heart of the reactor is a vertical cylindrical cavity receiver $(80 \mathrm{~mm}$ diameter) with a conical bottom (total height $115 \mathrm{~mm}$ ). Extensive testing of continuous solar biomass gasification was performed and the influence of different ligno-cellulosic biomass feedstocks (in terms of composition, LHV and particle size), steam/biomass ratios, biomass feeding rates, carrier gas flow rates and reaction temperatures $\left(1,100-1,400^{\circ} \mathrm{C}\right)$ on syngas productivity and chemical storage efficiency (Chuayboon et al., 2018a; Chuayboon et al., 2018b) was assessed. Biomass feeding rate was optimized consistently with operating temperature, so as to achieve a chemical storage efficiency of $29 \%$ with carbon conversion degree exceeding 90\% (Chuayboon et al., 2019). The spouted bed configuration was also investigated for solarhybridized biomass gasification through partial oxy-combustion (Boujjat et al., 2019a). This concept was investigated both numerically and experimentally under real direct concentrated solar flux. Operation in hybrid conditions (solar/combustion) allowed to reach high temperature values, but at the expense of syngas yield and quality.

Despite the several solar gasifiers developed at laboratory scale, none has been scaled-up or commercialized due to the process high temperature, the large reactor volume needed to complete fuel conversion and the fluctuating syngas production. In this scenario, the integration of dual FB gasification systems with solar energy considering solid particles as energy carrier and energy storage material could represent a solution for large scale solid fuels gasification and liquid fuels production (Guo et al., 2015; Guo et al., 2017; Gómez-Barea et al., 2020; Suárez-Almeida et al., 2021).

\section{Solar-Driven Production of Chemicals and Materials}

CSP can be exploited for the production of chemicals and materials involving energy intensive endothermal processes.

Production of calcines for the cement industry is among these. Concrete is by far the most widely used building material worldwide, with an average of $3 \mathrm{t} \mathrm{yr}^{-1}$ of concrete per person. Concrete is based on cement, obtained by adding gypsum to clinker (Telschow et al., 2012). A raw meal of limestone/clay (about $80 \%$ limestone) is first preheated-calcined at about $800-1,000^{\circ} \mathrm{C}$, then burnt in a rotary kiln up to $1,400-1,500^{\circ} \mathrm{C}$ for standard (i.e. Portland) clinker production. A significant share of global $\mathrm{CO}_{2}$ emissions, i.e. about $0.9 \mathrm{t} \mathrm{CO}_{2}$ per ton of clinker, is released (Barcelo et al., 2014; Xu et al., 2015) from both fuel combustion and limestone calcination. The world clinker production results into about $6 \%$ of the global $\mathrm{CO}_{2}$ emissions, and $21 \%$ of the global industrial $\mathrm{CO}_{2}$ emissions. In this scenario, the use of solar energy to sustain endothermal limestone calcination could provide substantial advantages. Solar-driven limestone calcination has been extensively investigated with positive outcomes (Flamant et al., 1980; Imhof, 2000a; Imhof, 2000b; Meier et al., 2005; Meier et al., 2006; Abanades and André, 2018; Rosa, 2019; Moumin et al., 2019; Oliveira et al., 2019; Esence et al., 2020a; Esence et al., 2020b).

Flamant et al. (1980) pioneered this topic in 1980. They reported experimental tests in a directly irradiated ordinary (Type A) FB for $\mathrm{CaCO}_{3}$ decomposition. The reactor, made of transparent silica $\left(0.001 \mathrm{~m}^{2}\right.$ cross section area, $0.3 \mathrm{~m}$ height $)$, was located at the focus of a small solar furnace $(2 \mathrm{~kW})$. A reflector surrounding the FB was used to limit radiation losses. Addition of $1 \%_{\mathrm{wt}}$ graphite to the bed improved its optical properties, hence the overall efficiency. The importance of parameters such as particle diameter, bed porosity, fluidization regime and optical properties of the granular material on the reactor performance was highlighted for the first time. Limestone calcination was successfully demonstrated, with a thermal efficiency of 0.20 for partial decomposition (up to $80 \%$ ) and of $0.10-0.15$ for complete calcination. A techno-economic feasibility analysis by González and Flamant (2014) confirms that there is no relevant technical barrier to integration of CSP in cement production, but thermal losses of the solar plant must be less than $45 \%$ to obtain an acceptable rate of return.

Tregambi et al. (2018b) investigated limestone calcination for clinker production in a directly irradiated ordinary (Type A) FB reactor. CSP was simulated with an array of three short-arc Xelamps, $4 \mathrm{~kW}_{\mathrm{e}}$ each, coupled with elliptical reflectors $\left(3 \mathrm{MW} \mathrm{m}^{-2}\right.$ peak flux, $3.2 \mathrm{~kW}_{\text {th }}$ total irradiated power). The reactivity of $\mathrm{CaO}$, produced by solar-driven $\mathrm{CaCO}_{3}$ calcination, combined with commercial clay in the formulation of Portland cement, was scrutinized with a focus on the influence of the different, and possibly more severe, thermal history experienced by particles in directly irradiated FB calcination. The feasibility of limestone FB solar-driven calcination to produce lime for the clinkerization process was demonstrated. Through burnability tests, it was observed that the use of solar $\mathrm{CaO}$ does not change the burnability easiness of the raw meal for Portland clinker, despite the local overheating experienced by limestone particles in solar-driven calcination. The clinker produced at $1,500^{\circ} \mathrm{C}$ with solar $\mathrm{CaO}$ was well within the ranges designated for commercial products, and the cement behavior upon hydration was comparable to the Portland cement base-case.

Esence et al. developed the shallow cross-flow FB reactor (Type I in Table 2) for continuous thermal processing of minerals. The goal of obtaining a product of more uniform properties was pursued by establishing a solids flow pattern approaching plug-flow. A first prototype was tested at the $1 \mathrm{MW}_{\text {th }}$ Odeillo's solar furnace for dolomite calcination (Esence et al., 2020a). At the achieved temperature levels (about $800^{\circ} \mathrm{C}$ ), only the $\mathrm{MgCO}_{3}$ core of the sample was calcined, with an overall efficiency of $6.4 \%$ if referring to the reaction heat, and of $16.8 \%$ if including the sensible contribution. The reactor design was eventually improved (Esence et al., 2020b) by careful optimization of the front wall irradiation, and tested for limestone calcination. Under the best experimental conditions, a continuous stream of $20 \mathrm{~kg} \mathrm{~h}^{-1}$ was calcined to $95 \%$, with an overall thermal efficiency of $17 \%$ (accounting only for reaction heat) or $29 \%$ (reaction plus sensible heat contributions). 
Ouaida et al. (1985) investigated reduction of ilmenite $\left(\mathrm{FeTiO}_{3}\right)$ in a directly irradiated ordinary (Type A) FB reactor with the aim of selectively reducing iron oxide. Titania-rich products may be further chemically treated to obtain $\mathrm{TiO}_{2}$. Experiments were performed in a $6.5 \mathrm{~kW}$ solar furnace at Odeillo, using particles within $80-125$ and $125-200 \mu \mathrm{m} . \mathrm{CH}_{4}$ and a mixture of $\mathrm{H}_{2}(40 \%)$ in Ar were tested as reducing gas. Bed agglomeration and associated channeling were observed during the tests. Best performance was obtained when working with $\mathrm{CH}_{4}$ at $900^{\circ} \mathrm{C}$, with a reduction extent of $70 \%$.

Steinfeld et al. (1993) investigated the use of a directly irradiated FB for reduction of iron oxide ores with natural gas, with simultaneous syngas generation from reforming/cracking of $\mathrm{CH}_{4}$, catalyzed by the freshly produced iron particles. Experiments were performed in a solar furnace at the Paul Scherrer Institute using a quartz Type A FB reactor, $20 \mathrm{~mm}$ diameter, located within a steel cylindrical receiver with gold electroplated inner walls to reduce IR thermal losses. Fine $(2 \mu \mathrm{m})$ $\mathrm{Fe}_{3} \mathrm{O}_{4}$ powder was mixed with silica grain in 1:5 ratio to enable fluidization. Peak solar flux was $900 \mathrm{~kW} \mathrm{~m}^{-2}$, total power of about $1.1 \mathrm{~kW}$. Reduction was performed at 1,073-1,273 K fluidizing the bed with a mixture of $10 \% \mathrm{CH}_{4}$ in Ar. Complete conversion of $\mathrm{Fe}_{3} \mathrm{O}_{4}$ into $\mathrm{FeO}$ and $\mathrm{Fe}$ was obtained, without relevant carbon deposition. Photo-enhancement of reaction kinetics was not ruled out. Particles sticking and local overheating induced recrystallization and loss of transmittance of the reactor quartz walls. Reduction of $\mathrm{ZnO}$ with $\mathrm{CH}_{4}$, yielding metallic zinc and syngas, was tested by Steinfeld et al. (1995) in the same apparatus, equipped with a compound parabolic concentrator to provide uniform irradiation and boost concentration. The bed consisted of a 1:1 mixture of fine $(2 \mu \mathrm{m}) \mathrm{ZnO}$ powder and $\mathrm{Al}_{2} \mathrm{O}_{3}$ grains, fluidized by a mixture of $10 \% \mathrm{CH}_{4}$ in Ar. A total power of $2.9 \mathrm{~kW}$ was delivered to the reactor, and process temperature was of about $1,373 \mathrm{~K}$. During the course of the reaction, gaseous $\mathrm{Zn}$ was produced and collected in a cold-finger condenser. Negligible amount of carbon was formed, spotted by the appearance of a greyish color on the $\mathrm{Al}_{2} \mathrm{O}_{3}$ particles. The same experimental apparatus was used by Steinfeld et al. (1997) to investigate endothermal cracking of hydrocarbons, and in particular of $\mathrm{CH}_{4}$, to produce filamentous carbon for application in lightweight composite materials, with simultaneous $\mathrm{H}_{2}$ generation. The FB inventory was a mixture of Ni-based catalyst with $\mathrm{Al}_{2} \mathrm{O}_{3}$ grains. Concentration of the incident solar radiation was kept within 600 suns to avoid excessive overheating, and temperature below $850 \mathrm{~K}$ to avoid catalyst deactivation. The conversion degree of $\mathrm{CH}_{4}$ was $40 \%$ in a single pass of $0.6 \mathrm{~s}$ through the $5 \mathrm{~cm}$ deep bed. The deposited carbon consisted of 1-2 mm granules made of randomly interlaced filaments. A remarkable finding was that, from each catalyst particle, a single filament of the same particle diameter was produced.

Keller and Otomo (2020) recently proposed the use of CSP to convert $\mathrm{CO}_{2}$ and $\mathrm{H}_{2}$ into $\mathrm{CO}$ by thermochemical redox cycling in interconnected FBs, via the reverse water gas shift reaction.

Navarro et al. (2009) used an indirectly heated Type A FB reactor to perform solar thermal desorption of mercury and arsenic from soils polluted by mining operations. In their prototype, a $\mathrm{SiC}$ honeycomb was irradiated using a solar furnace at the Almeria Solar Platform, whence thermal power was transferred to the FB by means of a heat transfer gaseous medium to achieve process temperatures up to $500^{\circ} \mathrm{C}$. Testing on representative samples demonstrated that removal of $\mathrm{Hg}$ and $\mathrm{As}$ could only take place at temperatures above $400^{\circ} \mathrm{C}$, and strongly depends on how $\mathrm{Hg}$ or As are chemically bound. For instance, $\mathrm{Hg}$ in cinnabar and pyrite was not efficiently removed, as higher temperature would have been required. Altogether, $\mathrm{Hg}$ removal ranged within $12-87 \%$ and As removal within 5-77\%. The Authors conclude that operating temperatures of about $600^{\circ} \mathrm{C}$ could further boost the removal efficiency, especially when minerals decomposing at higher temperature are present in the soil. Using the same experimental apparatus, Ruiz-Bustinza et al. (2013) investigated the reduction of hematite to magnetite in a stream of $5 \% \mathrm{H}_{2}$ in $\mathrm{N}_{2}$. The aim of the process is to recycle waste steel by conversion into magnetite, whose separation is much easier due to its ferromagnetic properties. Reduction was performed at $750^{\circ} \mathrm{C}$ for $40 \mathrm{~min}$ with hematite pellets obtained from oxidation of mill scale, with $100 \%$ conversion to magnetite. The large specific heat of hematite effectively stabilized the process temperature upon fluctuations of incident input power.

Application of solar-driven mineral reduction was proposed by De Maria et al. (2001) to produce $\mathrm{O}_{2}$ on the moon by high temperature reduction of ilmenite, one of the main components in lunar soil, in a directly irradiated FB reactor (Type A, Table 2). As the particles found on the moon are characterized by fine diameter, the use of a sound-assisted FB reactor is suggested to overcome cohesive forces and promote fluidization.

Assessment of solar driven production of chemicals and materials has been mostly performed in ordinary FBs. Special designs (e.g. Type I) have only recently been investigated with positive impact on the improvement of product uniformity and yield.

\section{OUTLOOK OF SOLAR-DRIVEN FLUIDIZED BED TECHNOLOGIES AND OPEN ISSUES}

CSP will most likely play a significant role, together with solar PV, wind and bioresources, for power generation and "green" hydrogen production (Grube et al., 2020). CSP could offset its inherently larger capital costs thanks to its much smaller requirements for critical raw materials, especially when energy storage is implemented (Valero et al., 2018), and thanks to efficient heat and/or power generation. FBs in CSP could further bridge the gap with competing technologies in terms of LCOE and of Levelized Cost Of Hydrogen, as process temperatures well above those permitted by molten salts-based technologies may drive more exergetically efficient thermodynamic cycles or provide more valuable process heat. Some FB technologies are being successfully pioneered at pilot and demonstration scale, like the Magaldi peak radiative power $2 \mathrm{MW}_{\text {th }}$ beam-down $\mathrm{STEM}^{\circledR}$ plant and the $3 \mathrm{MW}_{\text {th }}$ fluidized particle-in-tube concept (Next-CSP, 2016). They will hopefully open the path to other technologies that are rapidly climbing the learning curve from the lab- and pre-pilot scale to the approach pilot-scale. 
Application of FBs to the very challenging field of solar chemistry is less mature, but it is growing fast. On-sun continuous solar-driven gasification of biomass has been demonstrated at the lab-scale. FB solar-assisted calcination of minerals has now reached the pilot-scale. The step toward the nearby field of solar-assisted CaL requires implementation of a dual interconnected FB reactor technology and has not been demonstrated as yet. Two-step thermocatalytic production of hydrogen has been demonstrated at a significant scale by discontinuous stagewise $\mathrm{CeO}_{2}$ redox shift. Full demonstration of solar-assisted solids looping cycles requires integration of a FB solar receiver into a dual interconnected $\mathrm{FB}$ reactor scheme. Lessons learned from the more mature field of FB-CSP for power generation/energy storage, together with experience on design/operation of dual interconnected FBs borrowed from nonsolar looping cycles, could provide in the near future the technological background for effective exploitation of FBs in solar-assisted looping cycles.

Additional challenges are related to the set-up of optimal collection/reflection optical schemes and radiation-bed interaction. The selection of tower-top vs beam-down scheme is still open to choice: the beam-down solution is less demonstrated and possibly somewhat less efficient than the tower-top scheme, but it warrants the far better operability of having the solar reactor located at the ground level. The choice between direct vs indirect heating of the bed is open to question. Direct bed irradiation is more efficient and may overcome many of the troublesome thermomechanical issues associated with absorbing cavities or walls subjected to highly concentrated radiative flux. Moreover, direct irradiation of FBs may exploit the volumetric nature of the receiver as the incident flux interacts with dilute solid suspensions in the splash zone of bubbling FBs, in the fountain of spouted beds, in the particleladen flow of fast FBs. On the other hand, directly irradiated schemes might suffer from operational and durability issues as transparent windows are subjected to fouling and opacification. Windowless direct irradiation solutions are also being considered, but still at the early exploration stage.

Finally, it is recalled that energy harvesting by CSP is inherently efficient as it exploits the entire spectrum of solar radiation, rather than selected spectral ranges. This is at odds with the currently reported thermal efficiencies of most solar-to-fuel or solar-to-chemical processes, that are far from being satisfactory. This is the consequence of the rather pioneering status of developments in this field. Considerable progress is being made along the path of more efficient thermal design of solar reactors, by featuring thermal integration and recuperation, as in

\section{REFERENCES}

Abanades, S., and André, L. (2018). Design and demonstration of a high temperature solar-heated rotary tube reactor for continuous particles calcination. Appl. Energ. 212, 1310-1320. doi:10.1016/j.apenergy.2018.01.019

Agu, C. E., Moldestad, B. M. E., and Pfeifer, C. (2020). Assessment of combustion and gasification behavior in a bubbling fluidized bed reactor: a comparison autothermal schemes, favored by the inherent properties of fluidized suspensions and by novel special designs of FB. Process scaling up from the inherently less efficient lab-scale to bigger scales is expected to further improve the overall efficiency of solar-to-X processes.

\section{CONCLUSION AND FUTURE PERSPECTIVES}

The growing interest for the direct exploitation of solar energy has greatly challenged the fluidization community to provide novel technological solutions. Fluidized beds provide excellent environments for many solar-driven physical and chemical processes due to an unsurpassed combination of excellent thermal properties, good interphase contact and mixing, particle mobility and conveyability, inherent flexibility of reactor design and operation. This review article has surveyed many cases in which fluidized beds have been re-designed in a novel and creative way to meet the specific requirements posed by the exploitation of concentrated solar radiation in energy conversion and storage and in solar-driven physical and chemical processing of granular materials. Most of the applications today are limited to lab- and pilot-scale realizations, that are now challenged by scale-up to the demonstration scale as a prerequisite for future deployment. The past and current successful accomplishments in this field and the growing interest for further applications of solar power lead to a very positive outlook of the application of fluidized beds to solar energy conversion and storage and to the fast-expanding domain of solar chemistry.

\section{AUTHOR CONTRIBUTIONS}

All authors listed have made a substantial, direct, and intellectual contribution to the work and approved it for publication.

\section{FUNDING}

The study has received financial support by the Ministry of Education, University and Research (MIUR)-Italy, in the frame of the project PON 2015-2020: “ARS01_00985 BIOFEEDSTOCK-Development of Integrated Technological Platforms for Residual Biomass Exploitation."

between biomass with and without chemical additives. Energy Fuels 34, 9654-9663. doi:10.1021/acs.energyfuels.0c01408

Almendros-Ibáñez, J. A., Fernández-Torrijos, M., Díaz-Heras, M., Belmonte, J. F., and Sobrino, C. (2019). A review of solar thermal energy storage in beds of particles: packed and fluidized beds. Solar Energy 192, 193-237. doi:10.1016/j. solener.2018.05.047

Alonso, E., Gallo, A., Roldán, M. I., Pérez-Rábago, C. A., and Fuentealba, E. (2017). Use of rotary kilns for solar thermal applications: review of developed studies 
and analysis of their potential. Solar Energy 144, 90-104. doi:10.1016/j.solener. 2017.01.004

Alonso, E., and Romero, M. (2015). Review of experimental investigation on directly irradiated particles solar reactors. Renew. Sustain. Energ. Rev. 41, 53-67. doi:10.1016/j.rser.2014.08.027

Alovisio, A., Chacartegui, R., Ortiz, C., Valverde, J. M., and Verda, V. (2017). Optimizing the CSP-calcium looping integration for thermochemical energy storage. Energ. Convers. Manage. 136, 85-98. doi:10.1016/j.enconman.2016. 12.093

Alva, G., Lin, Y., and Fang, G. (2018). An overview of thermal energy storage systems. Energy 144, 341-378. doi:10.1016/j.energy.2017.12.037

Ammendola, P., Raganati, F., Miccio, F., Murri, A. N., and Landi, E. (2020). Insights into utilization of strontium carbonate for thermochemical energy storage. Renew. Energ. 157, 769-781. doi:10.1016/j.renene.2020. 05.048

André, L., and Abanades, S. (2017). Evaluation and performances comparison of calcium, strontium and barium carbonates during calcination/carbonation reactions for solar thermochemical energy storage. J. Energ. Storage 13, 193-205. doi:10.1016/j.est.2017.07.014

André, L., Abanades, S., and Flamant, G. (2016). Screening of thermochemical systems based on solid-gas reversible reactions for high temperature solar thermal energy storage. Renew. Sustain. Energ. Rev. 64, 703-715. doi:10.1016/j. rser.2016.06.043

Angerer, M., Becker, M., Härzschel, S., Kröper, K., Gleis, S., Vandersickel, A., et al. (2018). Design of a MW-scale thermo-chemical energy storage reactor. Energ. Rep. 4, 507-519. doi:10.1016/j.egyr.2018.07.005

Ansart, R., García-Triñanes, P., Boissière, B., Benoit, H., Seville, J. P. K., and Simonin, O. (2017). Dense gas-particle suspension upward flow used as heat transfer fluid in solar receiver: PEPT experiments and 3D numerical simulations. Powder Tech. 307, 25-36. doi:10.1016/j.powtec.2016.11.006

Arastoopour, H. (2019). The critical contribution of chemical engineering to a pathway to sustainability. Chem. Eng. Sci. 203, 247-258. doi:10.1016/j.ces.2019. 03.069

Arribas, L., González-Aguilar, J., and Romero, M. (2018). Solar-driven thermochemical water-splitting by cerium oxide: determination of operational conditions in a directly irradiated fixed bed reactor. Energies 11, 2451-2515. doi:10.3390/en11092451

Bachovchin, D. M., Archer, D. H., and Neale, D. H. (1983). Heat transfer in a fluidized-bed solar thermal receiver. Aiche Symp. Ser. 79, 27-36.

Bailera, M., Lisbona, P., Romeo, L. M., and Díez, L. I. (2020). Calcium looping as chemical energy storage in concentrated solar power plants: carbonator modelling and configuration assessment. Appl. Therm. Eng. 172, 115186. doi:10.1016/j.applthermaleng.2020.115186

Barcelo, L., Kline, J., Walenta, G., and Gartner, E. (2014). Cement and carbon emissions. Mater. Struct. 47, 1055-1065. doi:10.1617/s11527-013-0114-5

Baud, G., Bezian, J. J., El Hafi, M., and Olalde, G. (2012). Radiative heat transfer modelling in a concentrated solar energy bubbling fluidized bed receiver using the Monte Carlo method. J. Phys. Conf. Ser. 369, 012030. doi:10.1088/17426596/369/1/012030

Bayon, A., Bader, R., Jafarian, M., Fedunik-Hofman, L., Sun, Y., Hinkley, J., et al. (2018). Techno-economic assessment of solid-gas thermochemical energy storage systems for solar thermal power applications. Energy 149, 473-484. doi:10.1016/j.energy.2017.11.084

Behar, O., Grange, B., and Flamant, G. (2020). Design and performance of a modular combined cycle solar power plant using the fluidized particle solar receiver technology. Energ. Convers. Manage. 220, 113108. doi:10.1016/j. enconman.2020.113108

Bellan, S., Gokon, N., Matsubara, K., Cho, H. S., and Kodama, T. (2018a). Heat transfer analysis of $5 \mathrm{~kW}$ th circulating fluidized bed reactor for solar gasification using concentrated Xe light radiation. Energy 160, 245-256. doi:10.1016/j.energy.2018.06.212

Bellan, S., Gokon, N., Matsubara, K., Cho, H. S., and Kodama, T. (2018b). Numerical and experimental study on granular flow and heat transfer characteristics of directly-irradiated fluidized bed reactor for solar gasification. Int. J. Hydrogen Energ. 43, 16443-16457. doi:10.1016/j.ijhydene. 2018.06.033

Bellan, S., Kodama, T., Matsubara, K., Gokon, N., Cho, H. S., and Inoue, K. (2019a). Heat transfer and particulate flow analysis of a $30 \mathrm{~kW}$ directly irradiated solar fluidized bed reactor for thermochemical cycling. Chem. Eng. Sci. 203, 511-525. doi:10.1016/j.ces.2018.09.012

Bellan, S., Kodama, T., Matsubara, K., Gokon, N., Cho, H. S., and Inoue, K. (2019b). Thermal performance of a $30 \mathrm{~kW}$ fluidized bed reactor for solar gasification: a CFD-DEM study. Chem. Eng. J. 360, 1287-1300. doi:10.1016/j.cej.2018.10.111

Bellan, S., Matsubara, K., Cheok, C. H., Gokon, N., and Kodama, T. (2017). CFDDEM investigation of particles circulation pattern of two-tower fluidized bed reactor for beam-down solar concentrating system. Powder Tech. 319, 228-237. doi:10.1016/j.powtec.2017.06.060

Bellan, S., Matsubara, K., Cho, H. S., Gokon, N., and Kodama, T. (2018c). A CFDDEM study of hydrodynamics with heat transfer in a gas-solid fluidized bed reactor for solar thermal applications. Int. J. Heat Mass Transfer 116, 377-392. doi:10.1016/j.ijheatmasstransfer.2017.09.015

Bellouard, Q., Abanades, S., and Rodat, S. (2017). Biomass gasification in an innovative spouted-bed solar reactor: experimental proof of concept and parametric study. Energy Fuels 31, 10933-10945. doi:10.1021/acs.energyfuels. $7 \mathrm{~b} 01839$

Bellouard, Q., Rodat, S., Abanades, S., Ravel, S., and Frayssines, P.-É. (2019). Design, simulation and experimental study of a directly-irradiated solar chemical reactor for hydrogen and syngas production from continuous solar-driven wood biomass gasification. Int. J. Hydrogen Energ. 44, 19193-19205. doi:10.1016/j.ijhydene.2018.04.147

Benitez-Guerrero, M., Sarrion, B., Perejon, A., Sanchez-Jimenez, P. E., PerezMaqueda, L. A., and Manuel Valverde, J. (2017). Large-scale high-temperature solar energy storage using natural minerals. Solar Energ. Mater. Solar Cells 168, 14-21. doi:10.1016/j.solmat.2017.04.013

Benoit, H., Pérez López, I., Gauthier, D., Sans, J.-L., and Flamant, G. (2015). Onsun demonstration of a $750^{\circ} \mathrm{C}$ heat transfer fluid for concentrating solar systems: dense particle suspension in tube. Solar Energy 118, 622-633. doi:10.1016/j.solener.2015.06.007

Berber, R., and Fletcher, E. A. (1988). Extracting oil from shale using solar energy. Energy 13, 13-23. doi:10.1016/0360-5442(88)90074-6

Berruti, F., Scott, D. S., and Rhodes, E. (1986). Measuring and modelling lateral solid mixing in a three-dimensional batch gas-solid fluidized bed reactor. Can. J. Chem. Eng. 64, 48-56. doi:10.1002/cjce.5450640107

Blamey, J., Anthony, E. J., Wang, J., and Fennell, P. S. (2010). The calcium looping cycle for large-scale $\mathrm{CO}_{2}$ capture. Prog. Energ. Combustion Sci. 36, 260-279. doi:10.1016/j.pecs.2009.10.001

Block, T., Knoblauch, N., and Schmücker, M. (2014). The cobalt-oxide/iron-oxide binary system for use as high temperature thermochemical energy storage material. Thermochim. Acta 577, 25-32. doi:10.1016/j.tca.2013.11.025

Boissiere, B., Ansart, R., Gauthier, D., Flamant, G., and Hemati, M. (2015). Experimental hydrodynamic study of gas-particle dense suspension upward flow for application as new heat transfer and storage fluid. Can. J. Chem. Eng. 93, 317-330. doi:10.1002/cjce.22087

Boot-Handford, M. E., Abanades, J. C., Anthony, E. J., Blunt, M. J., Brandani, S., Mac Dowell, N., et al. (2014). Carbon capture and storage update. Energy Environ. Sci. 7, 130-189. doi:10.1039/c3ee42350f

Boujjat, H., Rodat, S., Chuayboon, S., and Abanades, S. (2020). Experimental and CFD investigation of inert bed materials effects in a high-temperature conical cavity-type reactor for continuous solar-driven steam gasification of biomass. Chem. Eng. Sci. 228, 115970. doi:10.1016/j.ces.2020.115970

Boujjat, H., Rodat, S., Chuayboon, S., and Abanades, S. (2019a). Experimental and numerical study of a directly irradiated hybrid solar/combustion spouted bed reactor for continuous steam gasification of biomass. Energy 189, 116118. doi:10.1016/j.energy.2019.116118

Boujjat, H., Rodat, S., Chuayboon, S., and Abanades, S. (2019b). Numerical simulation of reactive gas-particle flow in a solar jet spouted bed reactor for continuous biomass gasification. Int. J. Heat Mass Transfer 144, 118572. doi:10. 1016/j.ijheatmasstransfer.2019.118572

Briongos, J. V., Gómez-Hernández, J., González-Gómez, P. A., and Serrano, D. (2018). Two-phase heat transfer model of a beam-down gas-solid fluidized bed solar particle receiver. Solar Energy 171, 740-750. doi:10.1016/j.solener.2018. 07.016

Carrillo, A. J., González-Aguilar, J., Romero, M., and Coronado, J. M. (2019). Solar energy on demand: a review on high temperature thermochemical heat storage systems and materials. Chem. Rev. 119, 4777-4816. doi:10.1021/acs.chemrev. $8 \mathrm{~b} 00315$ 
Chacartegui, R., Alovisio, A., Ortiz, C., Valverde, J. M., Verda, V., and Becerra, J. A. (2016). Thermochemical energy storage of concentrated solar power by integration of the calcium looping process and a $\mathrm{CO}_{2}$ power cycle. Appl. Energ. 173, 589-605. doi:10.1016/j.apenergy.2016.04.053

Chen, X., Zhang, Z., Qi, C., Ling, X., and Peng, H. (2018). State of the art on the high-temperature thermochemical energy storage systems. Energ. Convers. Manage. 177, 792-815. doi:10.1016/j.enconman.2018.10.011

Chirone, R., Salatino, P., Ammendola, P., Solimene, R., Magaldi, M., Sorrenti, R., et al. (2013). "Development of a novel concept of solar receiver/thermal energy storage system based on compartmented dense gas fluidized beds," in Proceedings of the 14th international conference on fluidization-from fundamentals to products, Noordwijkerhout, Netherlands, May, 2013.

Cho, H. S., Gokon, N., Kodama, T., Kang, Y. H., and Lee, H. J. (2015). Improved operation of solar reactor for two-step water-splitting $\mathrm{H}_{2}$ production by ceriacoated ceramic foam device. Int. J. Hydrogen Energ. 40, 114-124. doi:10.1016/j. ijhydene.2014.10.084

Chuayboon, S., and Abanades, S. (2020). An overview of solar decarbonization processes, reacting oxide materials, and thermochemical reactors for hydrogen and syngas production. Int. J. Hydrogen Energ., 45, 25783. doi:10.1016/j. ijhydene.2020.04.098

Chuayboon, S., Abanades, S., and Rodat, S. (2018a). Comprehensive performance assessment of a continuous solar-driven biomass gasifier. Fuel Process. Tech. 182, 1-14. doi:10.1016/j.fuproc.2018.10.016

Chuayboon, S., Abanades, S., and Rodat, S. (2018b). Experimental analysis of continuous steam gasification of wood biomass for syngas production in a hightemperature particle-fed solar reactor. Chem. Eng. Process. Process Intensif. 125, 253-265. doi:10.1016/j.cep.2018.02.004

Chuayboon, S., Abanades, S., and Rodat, S. (2019). Insights into the influence of biomass feedstock type, particle size and feeding rate on thermochemical performances of a continuous solar gasification reactor. Renew. Energ. 130, 360-370. doi:10.1016/j.renene.2018.06.065

Coppola, A., Esposito, A., Montagnaro, F., De Tommaso, G., Scala, F., and Salatino, P. (2019a). Effect of exposure to $\mathrm{SO}_{2}$ and $\mathrm{H}_{2} \mathrm{O}$ during the carbonation stage of fluidised bed calcium looping on the performance of sorbents of different nature. Chem. Eng. J. 377, 120626. doi:10.1016/j.cej.2018.12.086

Coppola, A., Esposito, A., Montagnaro, F., Iuliano, M., Scala, F., and Salatino, P. (2019b). The combined effect of $\mathrm{H}_{2} \mathrm{O}$ and $\mathrm{SO}_{2}$ on $\mathrm{CO}_{2}$ uptake and sorbent attrition during fluidised bed calcium looping. Proc. Combustion Inst. 37, 4379-4387. doi:10.1016/j.proci.2018.08.013

Coppola, A., Scala, F., Salatino, P., and Montagnaro, F. (2013). Fluidized bed calcium looping cycles for $\mathrm{CO}_{2}$ capture under oxy-firing calcination conditions: Part 1. Assessment of six limestones. Chem. Eng. J. 231, 537-543. doi:10.1016/j. cej.2013.07.113

Criado, Y. A., Alonso, M., Abanades, J. C., and Anxionnaz-Minvielle, Z. (2014). Conceptual process design of a $\mathrm{CaO} / \mathrm{Ca}(\mathrm{OH})_{2}$ thermochemical energy storage system using fluidized bed reactors. Appl. Therm. Eng. 73, 1087-1094. doi:10. 1016/j.applthermaleng.2014.08.065

Criado, Y. A., Huille, A., Rougé, S., and Abanades, J. C. (2017). Experimental investigation and model validation of a $\mathrm{CaO} / \mathrm{Ca}(\mathrm{OH})_{2}$ fluidized bed reactor for thermochemical energy storage applications. Chem. Eng. J. 313, 1194-1205. doi:10.1016/j.cej.2016.11.010

Davis, D., Jafarian, M., Chinnici, A., Saw, W. L., and Nathan, G. J. (2019a). Thermal performance of vortex-based solar particle receivers for sensible heating. Solar Energy 177, 163-177. doi:10.1016/j.solener.2018.10.086

Davis, D., Troiano, M., Chinnici, A., Saw, W. L., Lau, T., Solimene, R., et al. (2020). Particle residence time distributions in a vortex-based solar particle receiverreactor: an experimental, numerical and theoretical study. Chem. Eng. Sci. 214, 115421. doi:10.1016/j.ces.2019.115421

Davis, D., Troiano, M., Chinnici, A., Saw, W. L., Lau, T., Solimene, R., et al. (2019b). Particle residence time distributions in a vortex-based solar particle receiverreactor: the influence of receiver tilt angle. Solar Energy 190, 126-138. doi:10. 1016/j.solener.2019.07.078

De Maria, G., Brunetti, B., Trionfetti, G., and Ferro, D. (2001). Solar energy fluidized bed reduction of ilmenite with hydrogen and methane at high temperature. SAE Tech. Pap. 2001-01-2414 doi:10.4271/2001-01-2414

Deutsch, M., Horvath, F., Knoll, C., Lager, D., Gierl-Mayer, C., Weinberger, P., et al. (2017). High-temperature energy storage: kinetic investigations of the
$\mathrm{CuO} / \mathrm{Cu}_{2} \mathrm{O}$ reaction cycle. Energy Fuels 31, 2324-2334. doi:10.1021/acs. energyfuels.6b02343

Díaz-Heras, M., Barreneche, C., Belmonte, J. F., Calderón, A., Fernández, A. I., and Almendros-Ibáñez, J. A. (2020a). Experimental study of different materials in fluidized beds with a beam-down solar reflector for CSP applications. Solar Energy 211, 683-699. doi:10.1016/j.solener.2020.07.011

Díaz-Heras, M., Belmonte, J. F., and Almendros-Ibáñez, J. A. (2021a). Experimental observations on directly irradiated fluidized beds: even and uneven fluidization. Exp. Therm. Fluid Sci. 120, 110242. doi:10.1016/j. expthermflusci.2020.110242

Díaz-Heras, M., Calderón, A., Navarro, M., Almendros-Ibáñez, J. A., Fernández, A. I., and Barreneche, C. (2021b). Characterization and testing of solid particles to be used in CSP plants: aging and fluidization tests. Solar Energ. Mater. Solar Cells 219, 110793. doi:10.1016/j.solmat.2020.110793

Díaz-Heras, M., Moya, J. D., Belmonte, J. F., Córcoles-Tendero, J. I., Molina, A. E., and Almendros-Ibáñez, J. A. (2020b). CSP on fluidized particles with a beamdown reflector: comparative study of different fluidization technologies. Solar Energy 200, 76-88. doi:10.1016/j.solener.2019.09.006

Durán-Martín, J. D., Sánchez Jimenez, P. E., Valverde, J. M., Perejón, A., Arcenegui-Troya, J., García Triñanes, P., et al. (2020). Role of particle size on the multicycle calcium looping activity of limestone for thermochemical energy storage. J. Adv. Res. 22, 67-76. doi:10.1016/j.jare.2019.10.008

Edwards, S. E. B., and Materić, V. (2012). Calcium looping in solar power generation plants. Solar Energy 86, 2494-2503. doi:10.1016/j.solener.2012. 05.019

Erans, M., Manovic, V., and Anthony, E. J. (2016). Calcium looping sorbents for $\mathrm{CO}_{2}$ capture. Appl. Energ. 180, 722-742. doi:10.1016/j.apenergy.2016.07.074

Esence, T., Benoit, H., Poncin, D., Tessonneaud, M., and Flamant, G. (2020a). A shallow cross-flow fluidized-bed solar reactor for continuous calcination processes. Solar Energy 196, 389-398. doi:10.1016/j.solener.2019.12.029

Esence, T., Guillot, E., Tessonneaud, M., Sans, J.-L., and Flamant, G. (2020b). Solar calcination at pilot scale in a continuous flow multistage horizontal fluidized bed. Solar Energy 207, 367-378. doi:10.1016/j.solener.2020.06.098

Falter, C., and Pitz-Paal, R. (2018). Energy analysis of solar thermochemical fuel production pathway with a focus on waste heat recuperation and vacuum generation. Solar Energy 176, 230-240. doi:10.1016/j.solener.2018.10.042

Farsi, A., and Dincer, I. (2019). Thermodynamic assessment of a hybrid particlebased concentrated solar power plant using fluidized bed heat exchanger. Solar Energy 179, 236-248. doi:10.1016/j.solener.2018.12.046

Ferriere, A., Chomette, S., Rojas, E., Caruncho, J.-M., Fluri, T., Ipse, D., et al. (2019). The POLYPHEM project: an innovative small-scale solar thermal combined cycle. AIP Conf. Proc. 2126, 030022. doi:10.1063/1.5117534

Flamant, G., Gauthier, D., Benoit, H., Sans, J.-L., Garcia, R., Boissière, B., et al. (2013). Dense suspension of solid particles as a new heat transfer fluid for concentrated solar thermal plants: on-sun proof of concept. Chem. Eng. Sci. 102, 567-576. doi:10.1016/j.ces.2013.08.051

Flamant, G., Gauthier, D., Boudhari, C., and Flitris, Y. (1988). A 50 kW fluidized bed high temperature solar receiver: heat transfer analysis. J. Sol. Energ. Eng. Trans. ASME 110, 313-320. doi:10.1115/1.3268273

Flamant, G., and Hemati, M. (2010). Device for collecting solar energy. French Patent No. 1058565, 20 October 2010. PCT extension.No.WO 2012/052661 A2.

Flamant, G., Hernandez, D., Bonet, C., and Traverse, J.-P. (1980). Experimental aspects of the thermochemical conversion of solar energy; Decarbonation of $\mathrm{CaCO}_{3}$. Solar Energy 24, 385-395. doi:10.1016/0038-092X(80)90301-1

Flamant, G., and Olalde, G. (1983). High temperature solar gas heating comparison between packed and fluidized bed receivers-I. Solar Energy 31, 463-471. doi:10. 1016/0038-092X(83)90050-6

Flamant, G. (1982). Theoretical and experimental study of radiant heat transfer in a solar fluidized-bed receiver. Aiche J. 28, 529-535. doi:10.1002/aic.690280402

Flegkas, S., Birkelbach, F., Winter, F., Freiberger, N., and Werner, A. (2018). Fluidized bed reactors for solid-gas thermochemical energy storage concepts-modelling and process limitations. Energy 143, 615-623. doi:10. 1016/j.energy.2017.11.065

García-Triñanes, P., Seville, J. P. K., Ansart, R., Benoit, H., Leadbeater, T. W., and Parker, D. J. (2018). Particle motion and heat transfer in an upward-flowing dense particle suspension: application in solar receivers. Chem. Eng. Sci. 177, 313-322. doi:10.1016/j.ces.2017.11.041 
Glicksman, L. R., Azzola, J., and Modlin, J. (1988). Fluidized bed solar collector. J. Sol. Energ. Eng. Trans. ASME 110, 321-326. doi:10.1115/1.3268274

Gokon, N., Izawa, T., Abe, T., and Kodama, T. (2014). Steam gasification of coal cokes in an internally circulating fluidized bed of thermal storage material for solar thermochemical processes. Int. J. Hydrogen Energ. 39, 11082-11093. doi:10.1016/j.ijhydene.2014.05.124

Gokon, N., Izawa, T., and Kodama, T. (2015). Steam gasification of coal cokes by internally circulating fluidized-bed reactor by concentrated Xe-light radiation for solar syngas production. Energy 79, 264-272. doi:10.1016/j.energy.2014. 11.012

Gokon, N., Kumaki, S., Miyaguchi, Y., Bellan, S., Kodama, T., and Cho, H. (2019). Development of a $5 \mathrm{kWth}$ internally circulating fluidized bed reactor containing quartz sand for continuously-fed coal-coke gasification and a beam-down solar concentrating system. Energy 166, 1-16. doi:10.1016/j. energy.2018.10.036

Gokon, N., Mataga, T., Kondo, N., and Kodama, T. (2011). Thermochemical two-step water splitting by internally circulating fluidized bed of $\mathrm{NiFe}_{2} \mathrm{O}_{4}$ particles: successive reaction of thermal-reduction and waterdecomposition steps. Int. J. Hydrogen Energ. 36, 4757-4767. doi:10. 1016/j.ijhydene.2011.01.076

Gokon, N., Mizuno, T., Takahashi, S., and Kodama, T. (2006). "A two-step water splitting with ferrite particles and its new reactor concept using an internally circulating fludized-bed," in Proceedings of ISEC2006 ASME international solar energy conference, Denver CO, July, 2006. Editors J. H. Morehouse and M. Krarti (Denver, CO: ASME), 1-10. doi:10.1115/ISEC2006-99063

Gokon, N., Ono, R., Hatamachi, T., Liuyun, L., Kim, H.-J., and Kodama, T. (2012). $\mathrm{CO}_{2}$ gasification of coal cokes using internally circulating fluidized bed reactor by concentrated Xe-light irradiation for solar gasification. Int. J. Hydrogen Energ. 37, 12128-12137. doi:10.1016/j.ijhydene.2012.05.133

Gokon, N., Takahashi, S., Yamamoto, H., and Kodama, T. (2008). Thermochemical two-step water-splitting reactor with internally circulating fluidized bed for thermal reduction of ferrite particles. Int. J. Hydrogen Energ. 33, 2189-2199. doi:10.1016/j.ijhydene.2008.02.044

Gómez-Barea, A., Suárez-Almeida, M., and Ghoniem, A. (2020). Analysis of fluidized bed gasification of biomass assisted by solar-heated particles. Biomass Conv. Bioref. 11, 143. doi:10.1007/s13399-020-00865-0

Gomez-Garcia, F., Gauthier, D., and Flamant, G. (2017). Design and performance of a multistage fluidised bed heat exchanger for particle-receiver solar power plants with storage. Appl. Energ. 190, 510-523. doi:10.1016/j.apenergy.2016. 12.140

Gómez-Hernández, J., González-Gómez, P. A., Briongos, J. V., and Santana, D. (2020). Technical feasibility analysis of a linear particle solar receiver. Solar Energy 195, 102-113. doi:10.1016/j.solener.2019.11.052

Gómez-Hernández, J., González-Gómez, P. Á., Ni-Song, T., Briongos, J. V., and Santana, D. (2018). Design of a solar linear particle receiver placed at the ground level. AIP Conf. Proc. 2033, 170005. doi:10.1063/1.5067169

González, R. S., and Flamant, G. (2014). Technical and economic feasibility analysis of using concentrated solar thermal technology in the cement production process: hybrid approach-a case study. J. Sol. Energ. Eng. Trans. ASME 136, 1-12. doi:10.1115/1.4026573

Gordillo, E. D., and Belghit, A. (2011). A bubbling fluidized bed solar reactor model of biomass char high temperature steam-only gasification. Fuel Process. Tech. 92, 314-321. doi:10.1016/j.fuproc.2010.09.021

Gregg, D. W., Taylor, R. W., Campbell, J. H., and Aiman, W. R. (1980). Solar coal gasification. Proc. Intersoc. Energ. Convers. Eng. Conf. 1, 633-636.

Grube, T., Reul, J., Reuß, M., Calnan, S., Monnerie, N., Schlatmann, R., et al. (2020). A techno-economic perspective on solar-to-hydrogen concepts through 2025. Sustain. Energ. Fuels 4, 5818-5834. doi:10.1039/d0se00896f

Guene Lougou, B., Shuai, Y., Pan, R., Chaffa, G., and Tan, H. (2018). Heat transfer and fluid flow analysis of porous medium solar thermochemical reactor with quartz glass cover. Int. J. Heat Mass Transfer 127, 61-74. doi:10.1016/j. ijheatmasstransfer.2018.06.153

Guene Lougou, B., Shuai, Y., Zhang, H., Ahouannou, C., Zhao, J., Kounouhewa, B. B., et al. (2020). Thermochemical $\mathrm{CO}_{2}$ reduction over $\mathrm{NiFe}_{2} \mathrm{O}_{4} @$ alumina filled reactor heated by high-flux solar simulator. Energy 197, 117267-117315. doi:10. 1016/j.energy.2020.117267

Guo, P., Saw, W. L., Van Eyk, P. J., Stechel, E. B., Ashman, P. J., and Nathan, G. J. (2017). System optimization for fischer-tropsch liquid fuels production via solar hybridized dual fluidized bed gasification of solid fuels. Energy Fuels 31, 2033-2043. doi:10.1021/acs.energyfuels.6b01755

Guo, P., Van Eyk, P. J., Saw, W. L., Ashman, P. J., Nathan, G. J., and Stechel, E. B. (2015). Performance assessment of Fischer-Tropsch liquid fuels production by solar hybridized dual fluidized bed gasification of lignite. Energy Fuels 29, 2738-2751. doi:10.1021/acs.energyfuels.5b00007

Haddad, I. M., and Elsayed, M. M. (1988). Transient performance of fluidized bed solar receiver at various parametric conditions. Solar Wind Tech. 5, 653-659. doi:10.1016/0741-983X(88)90063-X

Haseli, P., Jafarian, M., and Nathan, G. J. (2017). High temperature solar thermochemical process for production of stored energy and oxygen based on $\mathrm{CuO} / \mathrm{Cu}_{2} \mathrm{O}$ redox reactions. Solar Energy 153, 1-10. doi:10.1016/j.solener. 2017.05.025

He, F., Trainham, J., Parsons, G., Newman, J. S., and Li, F. (2014). A hybrid solarredox scheme for liquid fuel and hydrogen coproduction. Energ. Environ. Sci. 7, 2033-2042. doi:10.1039/c4ee00038b

Hirsch, D., Zedtwitz, and, P. V., Osinga, T., Kinamore, J., and Steinfeld, A. (2003). A new $75 \mathrm{~kW}$ high-flux solar simulator for high-temperature thermal and thermochemical research. J. Sol. Energ. Eng. Trans. ASME 125, 117-120. doi:10. $1115 / 1.1528922$

Ho, C. K. (2016). A review of high-temperature particle receivers for concentrating solar power. Appl. Therm. Eng. 109, 958-969. doi:10.1016/j.applthermaleng. 2016.04.103

Hopkins, M. W., DeJenga, C., and Antal, M. J. (1984). The flash pyrolysis of cellulosic materials using concentrated visible light. Solar Energy 32, 547-551. doi:10.1016/0038-092X(84)90269-X

Hoskins, A. L., Millican, S. L., Czernik, C. E., Alshankiti, I., Netter, J. C., Wendelin, T. J., et al. (2019). Continuous on-sun solar thermochemical hydrogen production via an isothermal redox cycle. Appl. Energ. 249, 368-376. doi:10. 1016/j.apenergy.2019.04.169

Imhof, A. (2000a). Calcination of limestone in a solar reactor. ZKG Int. 53, 504-509.

Imhof, A. (2000b). Solar Cement Plants-an interesting challenge for business and science. ZKG Int. 53, 448-456.

IPCC (2006). Guidelines for national greenhouse gas inventories. Editors H. S. Eggleston, L. Buendia, K. Miwa, T. Ngara, and K. Tanabe (Hayama, Japan: Institute for Global Environmental Strategies (IGES)).

IPCC (2019). 2019 refinement to the 2006 IPCC guidelines for national greenhouse gas inventories. Editors S. E. Calvo Buendia, K. Tanabe, A. Kranjc, J. Baasansuren, M. Fukuda, S. Ngarize, et al. (Geneva, Switzerland: IPCC).

IRENA (2020). Renewable power generation costs in 2019. Abu Dhabi, United Arab Emirates: International Renewable Energy Agency.

Kang, Q., Dewil, R., Degrève, J., Baeyens, J., and Zhang, H. (2018). Energy analysis of a particle suspension solar combined cycle power plant. Energ. Convers. Manage. 163, 292-303. doi:10.1016/j.enconman.2018.02.067

Kang, Q., Flamant, G., Dewil, R., Baeyens, J., Zhang, H. L., and Deng, Y. M. (2019). Particles in a circulation loop for solar energy capture and storage. Particuology 43, 149-156. doi:10.1016/j.partic.2018.01.009

Keller, M., and Otomo, J. (2020). CO production from $\mathrm{CO}_{2}$ and $\mathrm{H}_{2}$ via the rWGS reaction by thermochemical redox cycling in interconnected fluidized beds. J. $\mathrm{CO}_{2}$ Utilization 40, 101191. doi:10.1016/j.jcou.2020.101191

Kodama, T., Bellan, S., Gokon, N., and Cho, H. S. (2017a). Particle reactors for solar thermochemical processes. Solar Energy 156, 113-132. doi:10.1016/j.solener. 2017.05.084

Kodama, T., Cho, H. S., Inoue, K., Saito, T., Watanabe, S., Gokon, N., et al. (2019). Particles fluidized bed receiver/reactor with a beam-down solar concentrating optics: first performance test on two-step water splitting with ceria using a Miyazaki solar concentrating system. AIP Conf. Proc. 2126, 180011. doi:10. $1063 / 1.5117691$

Kodama, T., Enomoto, S.-i., Hatamachi, T., and Gokon, N. (2008). Application of an internally circulating fluidized bed for windowed solar chemical reactor with direct irradiation of reacting particles. J. Sol. Energ. Eng. Trans. ASME 130, 0145041. doi:10.1115/1.2807213

Kodama, T., Gokon, N., Cho, H. S., Bellan, S., Matsubara, K., and Inoue, K. (2018). Particle fluidized bed receiver/reactor with a beam-down solar concentrating optics: performance test of two-step water splitting with ceria particles using $30-\mathrm{kW}_{\text {th }}$ sun- simulator. AIP Conf. Proc. 2033, 130009. doi:10.1063/1.5067143 
Kodama, T., Gokon, N., Cho, H. S., Matsubara, K., Etori, T., Takeuchi, A., et al. (2016). Particles fluidized bed receiver/reactor with a beam-down solar concentrating optics: $30-\mathrm{kW}_{\text {th }}$ performance test using a big sun-simulator. AIP Conf. Proc. 1734, 120004. doi:10.1063/1.4949206

Kodama, T., Gokon, N., Cho, H. S., Matsubara, K., Kaneko, H., Senuma, K., et al. (2017b). Particles fluidized bed receiver/reactor tests with quartz sand particles using a $100-\mathrm{kW}_{\text {th }}$ beam-down solar concentrating system at Miyazaki. AIP Conf. Proc. 1850, 100012. doi:10.1063/1.4984469

Kodama, T., Gokon, N., Enomoto, S.-i., Itoh, S., and Hatamachi, T. (2010). Coal coke gasification in a windowed solar chemical reactor for beamdown optics. J. Sol. Energ. Eng. Trans. ASME 132, 1-6. doi:10.1115/1. 4002081

Kodama, T., and Gokon, N. (2007). Thermochemical cycles for high-temperature solar hydrogen production. Chem. Rev. 107, 4048-4077. doi:10.1021/cr050188a

Kodama, T. (2003). High-temperature solar chemistry for converting solar heat to chemical fuels. Prog. Energy Combust. Sci. 29, 567-597. doi:10.1016/S03601285(03)00059-5

Kodama, T., Kondoh, Y., Tamagawa, T., Funatoh, A., Shimizu, K.-I., and Kitayama, Y. (2002). Fluidized bed coal gasification with $\mathrm{CO}_{2}$ under direct irradiation with concentrated visible light. Energy Fuels 16, 1264-1270. doi:10.1021/ef020053x

Koenigsdorff, R., and Kienzle, P. (1991). Results of and prospects for research on direct-absorption fluidized bed solar receivers. Solar Energ. Mater. 24, 279-283. doi:10.1016/0165-1633(91)90068-V

Koepf, E., Villasmil, W., and Meier, A. (2016). Pilot-scale solar reactor operation and characterization for fuel production via the $\mathrm{Zn} / \mathrm{ZnO}$ thermochemical cycle. Appl. Energ. 165, 1004-1023. doi:10.1016/j.apenergy.2015.12.106

Le Gal, A., Grange, B., Tessonneaud, M., Perez, A., Escape, C., Sans, J.-L., et al. (2019). Thermal analysis of fluidized particle flows in a finned tube solar receiver. Solar Energy 191, 19-33. doi:10.1016/j.solener.2019.08.062

Lédé, J. (1999). Solar thermochemical conversion of biomass. Solar Energy 65, 3-13. doi:10.1016/s0038-092x(98)00109-1

Li, X., Shen, Y., Wei, L., He, C., Lapkin, A. A., Lipiński, W., et al. (2020). Hydrogen production of solar-driven steam gasification of sewage sludge in an indirectly irradiated fluidized-bed reactor. Appl. Energ. 261, 114229. doi:10.1016/j. apenergy.2019.114229

Lu, Y., Zhu, L., Agrafiotis, C., Vieten, J., Roeb, M., and Sattler, C. (2019). Solar fuels production: two-step thermochemical cycles with cerium-based oxides. Prog. Energ. Combustion Sci. 75, 100785. doi:10.1016/j.pecs.2019.100785

Ma, C., Zhou, Y., Wang, J., and Li, X. (2020a). Numerical study on solar spouted bed reactor for conversion of biomass into hydrogen-rich gas by steam gasification. Int. J. Hydrogen Energ. 45, 33136-33150. doi:10.1016/j.ijhydene. 2020.09.120

Ma, Z., Glatzmaier, G., and Mehos, M. (2014). Fluidized bed technology for concentrating solar power with thermal energy storage. J. Sol. Energ. Eng. Trans. ASME 136, 1-9. doi:10.1115/1.4027262

Ma, Z., Li, Y., Zhang, W., Wang, Y., Zhao, J., and Wang, Z. (2020b). Energy storage and attrition performance of limestone under fluidization during $\mathrm{CaO} / \mathrm{CaCO}_{3}$ cycles. Energy 207, 118291. doi:10.1016/j.energy.2020.118291

Magaldi (2020). Stem-solar thermo-electric Magaldi. Available at: https://www. magaldi.com/en/products-solutions/csp-concentrating-solar-power (Accessed October 08, 2020).

Marra, F. S., Troiano, M., Montagnaro, F., Salatino, P., and Solimene, R. (2017). Particle-wall interaction in entrained-flow slagging coal gasifiers: granular flow simulation and experiments in a cold flow model reactor. Int. J. Multiphase Flow 91, 142-154. doi:10.1016/j.ijmultiphaseflow.2017.01.011

Marti, J., Haselbacher, A., and Steinfeld, A. (2015). A numerical investigation of gas-particle suspensions as heat transfer media for high-temperature concentrated solar power. Int. J. Heat Mass Transfer 90, 1056-1070. doi:10. 1016/j.ijheatmasstransfer.2015.07.033

Marxer, D., Furler, P., Scheffe, J., Geerlings, H., Falter, C., Batteiger, V., et al. (2015). Demonstration of the entire production chain to renewable kerosene via solar thermochemical splitting of $\mathrm{H}_{2} \mathrm{O}$ and $\mathrm{CO}_{2}$. Energy Fuels 29, 3241-3250. doi:10. 1021/acs.energyfuels.5b00351

Matsubara, K., Sakai, H., Kazuma, Y., Sakurai, A., Kodama, T., Gokon, N., et al. (2015). Numerical modeling of a two-tower type fluidized receiver for high temperature solar concentration by a beam-down reflector system. Energ. Proced. 69, 487-496. doi:10.1016/j.egypro.2015.03.057
Matthews, L., and Lipiński, W. (2012). Thermodynamic analysis of solar thermochemical $\mathrm{CO}_{2}$ capture via carbonation/calcination cycle with heat recovery. Energy 45, 900-907. doi:10.1016/j.energy.2012.06.072

Medrano, M., Gil, A., Martorell, I., Potau, X., and Cabeza, L. F. (2010). State of the art on high-temperature thermal energy storage for power generation. Part 2Case studies. Renew. Sustain. Energ. Rev. 14, 56-72. doi:10.1016/j.rser.2009. 07.036

Megahed, I. E., Elsayed, M. M., and El-Refaee, M. M. (1988). Fluidized bed- solar concentrator thermal storage system performance. Wärme- und Stoffübertragung 23, 187-194. doi:10.1007/BF01807320

Meier, A., Bonaldi, E., Cella, G. M., Lipinski, W., and Wuillemin, D. (2006). Solar chemical reactor technology for industrial production of lime. Solar Energy 80, 1355-1362. doi:10.1016/j.solener.2005.05.017

Meier, A., Gremaud, N., and Steinfeld, A. (2005). Economic evaluation of the industrial solar production of lime. Energ. Convers. Manage. 46, 905-926. doi:10.1016/j.enconman.2004.06.005

Migliozzi, S., Paulillo, A., Chirone, R., Salatino, P., and Solimene, R. (2017). Hydrodynamics of compartmented fluidized beds under uneven fluidization conditions. Powder Tech. 316, 476-491. doi:10.1016/j.powtec.2016.12.052

Milanese, M., Colangelo, G., Iacobazzi, F., and de Risi, A. (2017a). Modeling of double-loop fluidized bed solar reactor for efficient thermochemical fuel production. Solar Energ. Mater. Solar Cells 160, 174-181. doi:10.1016/j. solmat.2016.10.028

Milanese, M., Colangelo, G., Laforgia, D., and de Risi, A. (2017b). Multi-parameter optimization of double-loop fluidized bed solar reactor for thermochemical fuel production. Energy 134, 919-932. doi:10.1016/j.energy.2017.06.088

Miller, D. C., Pfutzner, C. J., and Jackson, G. S. (2018). Heat transfer in counterflow fluidized bed of oxide particles for thermal energy storage. Int. J. Heat Mass Transfer 126, 730-745. doi:10.1016/j.ijheatmasstransfer.2018.05.165

Montagnaro, F., Tregambi, C., Salatino, P., Senneca, O., and Solimene, R. (2018). Modelling oxy-pyrolysis of sewage sludge in a rotary kiln reactor. Fuel 231, 468-478. doi:10.1016/j.fuel.2018.05.094

Moumin, G., Tescari, S., Sundarraj, P., de Oliveira, L., Roeb, M., and Sattler, C. (2019). Solar treatment of cohesive particles in a directly irradiated rotary kiln. Solar Energy 182, 480-490. doi:10.1016/j.solener.2019.01.093

Müller, R., Zedtwitz, P. v., Wokaun, A., and Steinfeld, A. (2003). Kinetic investigation on steam gasification of charcoal under direct high-flux irradiation. Chem. Eng. Sci. 58, 5111-5119. doi:10.1016/j.ces.2003.08.018

Muroyama, A. P., Guscetti, I., Schieber, G. L., Haussener, S., and Loutzenhiser, P. G. (2018). Design and demonstration of a prototype $1.5 \mathrm{~kW}$ th hybrid solar/ autothermal steam gasifier. Fuel 211, 331-340. doi:10.1016/j.fuel.2017.09.059

Muroyama, A., Shinn, T., Fales, R., and Loutzenhiser, P. G. (2014). Modeling of a dynamically-controlled hybrid solar/autothermal steam gasification reactor. Energy Fuels 28, 6520-6530. doi:10.1021/ef501535r

Murray, J., and Fletcher, E. A. (1994). Reaction of steam with cellulose in a fluidized bed using concentrated sunlight. Energy 19, 1083-1098. doi:10.1016/03605442(94)90097-3

Nathan, G. J., Dally, B. B., Alwahabi, Z. T., Van Eyk, P. J., Jafarian, M., and Ashman, P. J. (2017). Research challenges in combustion and gasification arising from emerging technologies employing directly irradiated concentrating solar thermal radiation. Proc. Combustion Inst. 36, 2055-2074. doi:10.1016/j.proci. 2016.07.044

Navarro, A., Cañadas, I., Martinez, D., Rodriguez, J., and Mendoza, J. L. (2009). Application of solar thermal desorption to remediation of mercury-contaminated soils. Solar Energy 83, 1405-1414. doi:10.1016/j.solener.2009.03.013

Next-CSP (2016). European Union's Horizon 2020 research and innovation programme, grant agreement No 727762. More info available at: http:// next-csp.eu/about/objectives/ (Accessed October 8, 2020).

Niklasson, F., Thunman, H., Johnsson, F., and Leckner, B. (2002). Estimation of solids mixing in a fluidized-bed combustor. Ind. Eng. Chem. Res. 41, 4663-4673. doi:10.1021/ie020173s

Nikulshina, V., Gebald, C., and Steinfeld, A. (2009). $\mathrm{CO}_{2}$ capture from atmospheric air via consecutive $\mathrm{CaO}$-carbonation and $\mathrm{CaCO}_{3}$-calcination cycles in a fluidized-bed solar reactor. Chem. Eng. J. 146, 244-248. doi:10.1016/j.cej. 2008.06.005

Nikulshina, V., and Steinfeld, A. (2009). $\mathrm{CO}_{2}$ capture from air via $\mathrm{CaO}$-carbonation using a solar-driven fluidized bed reactor-Effect of temperature and water vapor concentration. Chem. Eng. J. 155, 867-873. doi:10.1016/j.cej.2009.10.004 
Oliveira, F. A. C., Fernandes, J. C., Galindo, J., Rodríguez, J., Cañadas, I., Vermelhudo, V., et al. (2019). Portland cement clinker production using concentrated solar energy-a proof-of-concept approach. Solar Energy 183, 677-688. doi:10.1016/j.solener.2019.03.064

Ortiz, C., Romano, M. C., Valverde, J. M., Binotti, M., and Chacartegui, R. (2018). Process integration of Calcium-Looping thermochemical energy storage system in concentrating solar power plants. Energy 155, 535-551. doi:10.1016/j.energy. 2018.04.180

Ouaida, M. B., Badie, J. M., and Flamant, G. (1985). High temperature thermochemical treatment of ilmenite $\mathrm{FeTiO}_{3}$ in solar chemical reactors. Solar Wind Tech. 2, 15-24. doi:10.1016/0741-983X(85)90023-2

Padula, S., Tregambi, C., Solimene, R., Chirone, R., Troiano, M., and Salatino, P. (2021). A novel fluidized bed "thermochemical battery" for energy storage in concentrated solar thermal technologies. Energy Convers. Manag. 236, 113994. doi:10.1016/j.enconman.2021.113994

Pardo, P., Anxionnaz-Minvielle, Z., Rougé, S., Cognet, P., and Cabassud, M. (2014). $\mathrm{Ca}(\mathrm{OH})_{2} / \mathrm{CaO}$ reversible reaction in a fluidized bed reactor for thermochemical heat storage. Solar Energy 107, 605-616. doi:10.1016/j. solener.2014.06.010

Park, S. H., Yeo, C. E., Lee, M. J., and Kim, S. W. (2020). Effect of bed particle size on thermal performance of a directly-irradiated fluidized bed gas heater. Processes 8, 967. doi:10.3390/PR8080967

Pell, M., Dunson, J. B., and Knowlton, T. M. (2008). "Gas-solid operations and equipment," in Perry's chemical engineers' handbook. Editors D. W. Green and R. H. Perry (New York, NY: McGraw-Hill).

Peng, X., Yao, M., Root, T. W., and Maravelias, C. T. (2020). Design and analysis of concentrating solar power plants with fixed-bed reactors for thermochemical energy storage. Appl. Energ. 262, 114543. doi:10.1016/j. apenergy.2020.114543

Perez Lopez, I., Benoit, H., Gauthier, D., Sans, J. L., Guillot, E., Mazza, G., et al. (2016). On-sun operation of a $150 \mathrm{~kW}$ th pilot solar receiver using dense particle suspension as heat transfer fluid. Solar Energy 137, 463-476. doi:10.1016/j. solener.2016.08.034

Prieto, C., Cooper, P., Fernández, A. I., and Cabeza, L. F. (2016). Review of technology: thermochemical energy storage for concentrated solar power plants. Renew. Sustain. Energ. Rev. 60, 909-929. doi:10.1016/j.rser.2015.12.364

Puig-Arnavat, M., Tora, E. A., Bruno, J. C., and Coronas, A. (2013). State of the art on reactor designs for solar gasification of carbonaceous feedstock. Solar Energy 97, 67-84. doi:10.1016/j.solener.2013.08.001

Raganati, F., Chirone, R., and Ammendola, P. (2020). Calcium-looping for thermochemical energy storage in concentrating solar power applications: evaluation of the effect of acoustic perturbation on the fluidized bed carbonation. Chem. Eng. J. 392, 123658. doi:10.1016/j.cej. 2019.123658

Reed, S., Sugo, H., and Kisi, E. (2018). High temperature thermal storage materials with high energy density and conductivity. Solar Energy 163, 307-314. doi:10. 1016/j.solener.2018.02.005

Reich, L., Yue, L., Bader, R., and Lipiński, W. (2014). Towards solar thermochemical carbon dioxide capture via calcium oxide looping: a review. Aerosol Air Qual. Res. 14, 500-514. doi:10.4209/aaqr.2013.05.0169

REN21 (2020). Renewables 2020 global status report. Available at: http://www. ren21.net/resources/publications/ (Accessed October 8, 2020).

Reyes Urrutia, A., Benoit, H., Zambon, M., Gauthier, D., Flamant, G., and Mazza, G. (2016). Simulation of the behavior of a dense $\mathrm{SiC}$ particle suspension as an energy transporting vector using computational fluid dynamics (CFD). Chem. Eng. Res. Des. 106, 141-154. doi:10.1016/j.cherd.2015.12.008

Reyes-Belmonte, M. A., Sebastián, A., Spelling, J., Romero, M., and GonzálezAguilar, J. (2019). Annual performance of subcritical Rankine cycle coupled to an innovative particle receiver solar power plant. Renew. Energ. 130, 786-795. doi:10.1016/j.renene.2018.06.109

Rogelj, J., Shindell, D., Jiang, K., Fifita, S., Forster, P., Ginzburg, V., et al. (2018). IPCC special report on global warming of $1.5^{\circ} \mathrm{C}$ Chapter2-mitigation pathways compatible with $1.5^{\circ} \mathrm{C}$ in the context of sustainable development, 93-(174.) Available at: https://www.ipcc.ch/site/assets/uploads/sites/2/2019/ 02/SR15_Chapter2_Low_Res.pdf (Accessed October 8, 2020).

Rosa, L. G. (2019). Solar heat for materials processing: a review on recent achievements and a prospect on future trends. ChemEngineering 3, 83 . doi:10.3390/chemengineering3040083
Rougé, S., Criado, Y. A., Soriano, O., and Abanades, J. C. (2017). Continuous CaO/ $\mathrm{Ca}(\mathrm{OH})_{2}$ fluidized bed reactor for energy storage: first experimental results and reactor model validation. Ind. Eng. Chem. Res. 56, 844-852. doi:10.1021/acs. iecr.6b04105

Ruiz-Bustinza, I., Cañadas, I., Rodríguez, J., Mochón, J., Verdeja, L. F., GarciaCarcedo, F., et al. (2013). Magnetite production from steel wastes with concentrated solar energy. Steel Research Int. 84, 207-217. doi:10.1002/srin. 201200145

Sakellariou, K. G., Karagiannakis, G., Criado, Y. A., and Konstandopoulos, A. G. (2015). Calcium oxide based materials for thermochemical heat storage in concentrated solar power plants. Solar Energy 122, 215-230. doi:10.1016/j. solener.2015.08.011

Salatino, P., Ammendola, P., Bareschino, P., Chirone, R., and Solimene, R. (2016). Improving the thermal performance of fluidized beds for concentrated solar power and thermal energy storage. Powder Tech. 290, 97-101. doi:10.1016/j. powtec.2015.07.036

Salatino, P., and Solimene, R. (2017). Mixing and segregation in fluidized bed thermochemical conversion of biomass. Powder Tech. 316, 29-40. doi:10.1016/ j.powtec.2016.11.058

Sánchez Jiménez, P. E., Perejón, A., Benítez Guerrero, M., Valverde, J. M., Ortiz, C., and Pérez Maqueda, L. A. (2019). High-performance and low-cost macroporous calcium oxide based materials for thermochemical energy storage in concentrated solar power plants. Appl. Energ. 235, 543-552. doi:10.1016/j.apenergy.2018.10.131

Sarrión, B., Perejón, A., Sánchez-Jiménez, P. E., Pérez-Maqueda, L. A., and Valverde, J. M. (2018). Role of calcium looping conditions on the performance of natural and synthetic Ca-based materials for energy storage. J. $\mathrm{CO}_{2}$ Utilization 28, 374-384. doi:10.1016/j.jcou.2018.10.018

Sasse, C., and Ingel, G. (1993). The role of the optical properties of solids in solar direct absorption process. Solar Energ. Mater. Solar Cells 31, 61-73. doi:10. 1016/0927-0248(93)90007-P

Schmidt, M., Szczukowski, C., Roßkopf, C., Linder, M., and Wörner, A. (2014). Experimental results of a $10 \mathrm{~kW}$ high temperature thermochemical storage reactor based on calcium hydroxide. Appl. Therm. Eng. 62, 553-559. doi:10. 1016/j.applthermaleng.2013.09.020

Schwaiger, K., Haider, M., Hämmerle, M., Wünsch, D., Obermaier, M., Beck, M., et al. (2014). SandTES-an active thermal energy storage system based on the fluidization of powders. Energ. Proced. 49, 983-992. doi:10.1016/j.egypro.2014. 03.106

Sette, E., Pallarès, D., and Johnsson, F. (2014). Experimental evaluation of lateral mixing of bulk solids in a fluid-dynamically down-scaled bubbling fluidized bed. Powder Tech. 263, 74-80. doi:10.1016/j.powtec.2014.04.091

Shuai, Y., Guene Lougou, B., Zhang, H., Zhao, J., Ahouannou, C., and Tan, H. (2021). Heat transfer analysis of solar-driven high-temperature thermochemical reactor using NiFe-Aluminate RPCs. Int. J. Hydrogen Energ. 46, 10104. doi:10.1016/j.ijhydene.2020.03.240

Singh, A., Tescari, S., Lantin, G., Agrafiotis, C., Roeb, M., and Sattler, C. (2017). Solar thermochemical heat storage via the $\mathrm{Co}_{3} \mathrm{O}_{4} / \mathrm{CoO}$ looping cycle: storage reactor modelling and experimental validation. Solar Energy 144, 453-465. doi:10.1016/j.solener.2017.01.052

Solimene, R., Chirone, R., Chirone, R., and Salatino, P. (2017). Dynamic modeling of a solar receiver/thermal energy storage system based on a compartmented dense gas fluidized bed. AIP Conf. Proc. 1850, 080026. doi:10.1063/1.4984447

Solimene, R., Fenelli, P., Chirone, R., and Salatino, P. (2014). "Heat transfer phenomena in bubbling fluidized beds for concentrated solar power," in CFB-11: proceedings of the 11th international conference on fluidized bed technology. Beijing, China, May, 2014, 435-440.

Steinfeld, A., Frei, A., Kuhn, P., and Wuillemin, D. (1995). Solar thermal production of zinc and syngas via combined $\mathrm{ZnO}$-reduction and $\mathrm{CH}_{4}$ reforming processes. Int. J. Hydrogen Energ. 20, 793-804. doi:10.1016/03603199(95)00016-7

Steinfeld, A., Kirillov, V., Kuvshinov, G., Mogilnykh, Y., and Reller, A. (1997). Production of filamentous carbon and hydrogen by solarthermal catalytic cracking of methane. Chem. Eng. Sci. 52, 3599-3603. doi:10.1016/S00092509(97)00166-8

Steinfeld, A., Kuhn, P., and Karni, J. (1993). High-temperature solar thermochemistry: production of iron and synthesis gas by $\mathrm{Fe}_{3} \mathrm{O}_{4}$-reduction with methane. Energy 18, 239-249. doi:10.1016/0360-5442(93)90108-p 
$\mathrm{Su}, \mathrm{C}$., Duan, L., and Anthony, E. J. (2018). $\mathrm{CO}_{2}$ capture and attrition performance of competitive eco-friendly calcium-based pellets in fluidized bed. Greenhouse Gas Sci. Technol. 8, 1124-1133. doi:10.1002/ghg.1825

Suárez-Almeida, M., Gómez-Barea, A., Ghoniem, A. F., and Pfeifer, C. (2021). Solar gasification of biomass in a dual fluidized bed. Chem. Eng. J. 406, 126665. doi:10.1016/j.cej.2020.126665

Sulzgruber, V., Wünsch, D., Haider, M., and Walter, H. (2020a). Numerical investigation on the flow behavior of a novel fluidization based particle thermal energy storage (FP-TES). Energy 200, 117528. doi:10.1016/j.energy.2020.117528

Sulzgruber, V., Wünsch, D., Walter, H., and Haider, M. (2020b). FP-TES: fluidization based particle thermal energy storage, part II: experimental investigations. Energies 13, 4302. doi:10.3390/en13174302

Sunku Prasad, J., Muthukumar, P., Desai, F., Basu, D. N., and Rahman, M. M. (2019). A critical review of high-temperature reversible thermochemical energy storage systems. Appl. Energ. 254, 113733. doi:10.1016/j.apenergy. 2019.113733

Taylor, R. W., Berjoan, R., and Coutures, J. P. (1983). Solar gasification of carbonaceous materials. Solar Energy 30, 513-525. doi:10.1016/0038092x(83)90063-4

Telschow, S., Frandsen, F., Theisen, K., and Dam-Johansen, K. (2012). Cement formation-a success story in a black box: high temperature phase formation of portland cement clinker. Ind. Eng. Chem. Res. 51, 10983-11004. doi:10.1021/ ie300674j

Tescari, S., Singh, A., Agrafiotis, C., de Oliveira, L., Breuer, S., Schlögl-Knothe, B., et al. (2017). Experimental evaluation of a pilot-scale thermochemical storage system for a concentrated solar power plant. Appl. Energ. 189, 66-75. doi:10. 1016/j.apenergy.2016.12.032

Tregambi, C., Bareschino, P., Mancusi, E., Pepe, F., Montagnaro, F., Solimene, R., et al. (2021). Modelling of a concentrated solar power - photovoltaics hybrid plant for carbon dioxide capture and utilization via calcium looping and methanation. Energ. Convers. Manage. 230, 113792. doi:10.1016/j.enconman. 2020.113792

Tregambi, C., Bevilacqua, C., Cammarota, A., Chirone, R., Salatino, P., Solimene, R., et al. (2019a). Experimental characterization of granular materials for directly irradiated fluidized bed solar receivers. AIP Conf. Proc. 2126, 030060. doi:10.1063/1.5117572

Tregambi, C., Bevilacqua, C., Troiano, M., Solimene, R., and Salatino, P. (2020a). A novel autothermal fluidized bed reactor for concentrated solar thermal applications. Chem. Eng. J. 398, 125702. doi:10.1016/j.cej.2020. 125702

Tregambi, C., Chirone, R., Montagnaro, F., Salatino, P., and Solimene, R. (2016). Heat transfer in directly irradiated fluidized beds. Solar Energy 129, 85-100. doi:10.1016/j.solener.2016.01.057

Tregambi, C., Di Lauro, F., Montagnaro, F., Salatino, P., and Solimene, R. (2019b). 110th anniversary: calcium looping coupled with concentrated solar power for carbon capture and thermochemical energy storage. Ind. Eng. Chem. Res. 58, 21262-21272. doi:10.1021/acs.iecr.9b03083

Tregambi, C., Di Lauro, F., Montagnaro, F., Salatino, P., and Solimene, R. (2019c). Limestone calcination-carbonation in a fluidized bed reactor/receiver for thermochemical energy storage applications. AIP Conf. Proc. 2126, 210008. doi:10.1063/1.5117757

Tregambi, C., Montagnaro, F., Salatino, P., and Solimene, R. (2015). A model of integrated calcium looping for $\mathrm{CO}_{2}$ capture and concentrated solar power. Solar Energy 120, 208-220. doi:10.1016/j.solener.2015.07.017

Tregambi, C., Montagnaro, F., Salatino, P., and Solimene, R. (2017). Directly irradiated fluidized bed reactors for thermochemical processing and energy storage: application to calcium looping. AIP Conf. Proc. 1850, 090007. doi:10. 1063/1.4984456

Tregambi, C., Montagnaro, F., Salatino, P., and Solimene, R. (2019d). Solar-driven torrefaction of a lignin-rich biomass residue in a directly irradiated fluidized bed reactor. Combustion Sci. Tech. 191, 1609-1627. doi:10.1080/00102202. 2019.1607847

Tregambi, C., Padula, S., Galbusieri, M., Coppola, G., Montagnaro, F., Salatino, P., et al. (2020b). Directly irradiated fluidized bed reactor for thermochemical energy storage and solar fuels production. Powder Tech. 366, 460-469. doi:10. 1016/j.powtec.2020.02.045

Tregambi, C., Salatino, P., Solimene, R., and Montagnaro, F. (2018a). An experimental characterization of Calcium Looping integrated with concentrated solar power. Chem. Eng. J. 331, 794-802. doi:10.1016/j.cej. 2017.08.068

Tregambi, C., Solimene, R., Montagnaro, F., Salatino, P., Marroccoli, M., Ibris, N., et al. (2018b). Solar-driven production of lime for ordinary Portland cement formulation. Solar Energy 173, 759-768. doi:10.1016/j.solener.2018.08.018

Troiano, M., Cammarota, A., Tregambi, C., Chirone, R., Salatino, P., and Solimene, R. (2020a). Fluidized bed combustion of solid lignin-rich residues from bioethanol production. Powder Tech. 371, 170-179. doi:10.1016/j.powtec.2020.05.070

Troiano, M., Montagnaro, F., Salatino, P., and Solimene, R. (2017a). Experimental characterization of particle-wall interaction relevant to entrained-flow gasification of biomass. Fuel 209, 674-684. doi:10.1016/ j.fuel.2017.08.044

Troiano, M., Montagnaro, F., Solimene, R., and Salatino, P. (2019). Modelling entrained-flow slagging gasification of solid fuels with nearwall particle segregation. Chem. Eng. J. 377, 119962. doi:10.1016/j.cej. 2018.09.123

Troiano, M., Santagata, T., Montagnaro, F., Salatino, P., and Solimene, R. (2017b). Impact experiments of char and ash particles relevant to entrained-flow coal gasifiers. Fuel, 202, 665-674. doi:10.1016/j.fuel.2017.03.056

Troiano, M., Solimene, R., Montagnaro, F., and Salatino, P. (2020b). Char/ash deposition and near-wall segregation in slagging entrained-flow gasification of solid fuels: from experiments to closure equations. Fuel 264, 116864. doi:10. 1016/j.fuel.2019.116864

Valero, A., Valero, A., Calvo, G., and Ortego, A. (2018). Material bottlenecks in the future development of green technologies. Renew. Sustain. Energ. Rev. 93, 178-200. doi:10.1016/j.rser.2018.05.041

von Zedtwitz, P., Lipiński, W., and Steinfeld, A. (2007). Numerical and experimental study of gas-particle radiative heat exchange in a fluidized-bed reactor for steam-gasification of coal. Chem. Eng. Sci. 62, 599-607. doi:10.1016/ j.ces.2006.09.027

von Zedtwitz, P., and Steinfeld, A. (2005). Steam-gasification of coal in a fluidizedbed/packed-bed reactor exposed to concentrated thermal radiation modeling and experimental validation. Ind. Eng. Chem. Res. 44, 3852-3861. doi:10.1021/ ie $050138 \mathrm{w}$

Werther, J., Koenigsdorff, M., and Fischer, M. (1994). "Use of circulating fluidized beds as solar receivers," in Preprints of annual meeting society of chemical engineers, Sendai, Japan, March 28-30 1994, 60-61.

Wu, S., Zhou, C., Doroodchi, E., Nellore, R., and Moghtaderi, B. (2018). A review on high-temperature thermochemical energy storage based on metal oxides redox cycle. Energ. Convers. Manage. 168, 421-453. doi:10.1016/j.enconman. 2018.05.017

Wünsch, D., Sulzgruber, V., Haider, M., and Walter, H. (2020). FP-TES: a fluidisation-based particle thermal energy storage, part I: numerical investigations and bulk heat conductivity. Energies 13, 4298. doi:10.3390/ en13174298

Xu, D., Cui, Y., Li, H., Yang, K., Xu, W., and Chen, Y. (2015). On the future of Chinese cement industry. Cement Concrete Res. 78, 2-13. doi:10.1016/j. cemconres.2015.06.012

Yadav, D., and Banerjee, R. (2016). A review of solar thermochemical processes. Renew. Sustain. Energ. Rev. 54, 497-532. doi:10.1016/j.rser.2015.10.026

Yan, Y., Wang, K., Clough, P. T., and Anthony, E. J. (2020). Developments in calcium/chemical looping and metal oxide redox cycles for high-temperature thermochemical energy storage: a review. Fuel Process. Tech. 199, 106280. doi:10.1016/j.fuproc.2019.106280

Zhai, R., Li, C., Qi, J., and Yang, Y. (2016). Thermodynamic analysis of $\mathrm{CO}_{2}$ capture by calcium looping process driven by coal and concentrated solar power. Energ. Convers. Manage. 117, 251-263. doi:10.1016/j.enconman.2016.03.022

Zhang, H., Baeyens, J., Cáceres, G., Degrève, J., and Lv, Y. (2016a). Thermal energy storage: recent developments and practical aspects. Prog. Energ. Combustion Sci. 53, 1-40. doi:10.1016/j.pecs.2015.10.003

Zhang, H., Benoit, H., Gauthier, D., Degrève, J., Baeyens, J., López, I. P., et al. (2016b). Particle circulation loops in solar energy capture and storage: gas-solid flow and heat transfer considerations. Appl. Energ. 161, 206-224. doi:10.1016/j. apenergy.2015.10.005

Zhang, H., Benoit, H., Perez-Lopèz, I., Flamant, G., Tan, T., and Baeyens, J. (2017). High-efficiency solar power towers using particle suspensions as heat carrier in the receiver and in the thermal energy storage. Renew. Energ. 111, 438-446. doi:10.1016/j.renene.2017.03.101 
Zhang, S., and Wang, Z. (2019). Experimental and numerical investigations on the fluidized heat absorption inside quartz glass and metal tubes. Energies 12, 806. doi:10.3390/en12050806

Zhang, X., and Liu, Y. (2014). Performance assessment of $\mathrm{CO}_{2}$ capture with calcination carbonation reaction process driven by coal and concentrated solar power. Appl. Therm. Eng. 70, 13-24. doi:10.1016/j.applthermaleng. 2014.04.072

Zsembinszki, G., Solé, A., Barreneche, C., Prieto, C., Fernández, A., and Cabeza, L. (2018). Review of reactors with potential use in thermochemical energy storage in concentrated solar power plants. Energies 11, 2358. doi:10.3390/en 11092358
Conflict of Interest: The authors declare that the research was conducted in the absence of any commercial or financial relationships that could be construed as a potential conflict of interest.

Copyright (c) 2021 Tregambi, Troiano, Montagnaro, Solimene and Salatino. This is an open-access article distributed under the terms of the Creative Commons Attribution License (CC BY). The use, distribution or reproduction in other forums is permitted, provided the original author(s) and the copyright owner(s) are credited and that the original publication in this journal is cited, in accordance with accepted academic practice. No use, distribution or reproduction is permitted which does not comply with these terms. 